\title{
Multilayered Coatings for High-Temperature Steam Oxidation: TGA Studies up to $1000{ }^{\circ} \mathrm{C}$
}

\author{
T. Dudziak, E. Medvedovski, and M. Homa
}

(Submitted December 12, 2017; in revised form March 12, 2018; published online July 10, 2018)

\begin{abstract}
The aim of the study was to obtain a preliminary data focused on the steam oxidation performance of multilayered coatings deposited on 310 stainless steel and $800 \mathrm{H}$ Incoloy. The coatings were obtained through the aluminizing thermal diffusion technology with the formation of aluminides; some coating options had an additional top layer of selected composition. In this study, five different coating systems, as well as uncoated metals, were exposed at $1000{ }^{\circ} \mathrm{C}$ using thermogravimetric analysis instrumentation simulating an initial stage of steam oxidation corrosion. In this work, along with determination of the mass change of the samples, microanalyses using light optical microscopy, scanning electron microscopy (SEM) equipped with energy $x$-ray dispersive spectrometry (EDS), as well as surface micro-hardness determination, have been carried out. The designed coating systems demonstrated promising high-temperature steam oxidation performance with no breakaway degradation issues.
\end{abstract}

Keywords corrosion, high temperature, microscopy, protective coatings, steam oxidation, steel, thermogravimetry

\section{Introduction}

Coal-fired power generation is one of the key industrial technologies in the energy production worldwide. However, the coal-fired power generation technology, which is still used in many plants, is rather old and inefficient and creates a large $\mathrm{CO}_{2}$ emission. This old technology, which is based on subcritical conditions ( $\mathrm{SbC}$ ), requires low pressures and low temperatures of steam (Ref 1). The steam pressure and temperature are adequate to the steel materials used in operation, i.e., low-grade steels like T/P22 (2.5 wt.\% Cr), T/ P91 (9 wt.\% Cr) are used with limited functionality and temperature of below $600{ }^{\circ} \mathrm{C}$. Their applicability and performance are limited due to the formation of thick, non-protective oxide scales consisting of predominantly iron oxides. Furthermore, due to large emission of $\mathrm{CO}_{2}$ from subcritical conditions of power plants, the European Union introduced recent legislations, which demand the reduction in $\mathrm{CO}_{2}$ to about 20$30 \%$ by 2020 . Nevertheless, electric power generation from coal firing technology still can be maintained but through a more secure and sustainable route, using a new generation of coal power plants with operating temperatures above $700{ }^{\circ} \mathrm{C}$ or even more in regions of super heaters and re-heaters. According to the high-efficiency low-emission roadmap for coal technology, prepared by International Energy Agency in 2012, these old and inefficient coal-fired processes for subcritical conditions should be replaced by more advanced technologies utilizing new units with higher efficiency for ultra-supercritical conditions (USC) and advanced-ultra-supercritical conditions

T. Dudziak and M. Homa, Foundry Research Institute (FRI), Zakopianska 73, 30-418, Kraków, Poland; E. Medvedovski, Endurance Technologies Inc., 71 - 4511 Glenmore Trial SE, Calgary, AB T2C 2R9, Canada. Contact e-mail: tomasz.dudziak@ iod.krakow.pl.
(A-USC) steam parameters (Ref 2). With this regard, the coalfired processes not only require high temperatures but also require utilizing higher-purity oxidation conditions. Steel materials with $\mathrm{Cr}$ contents of $2-10 \%$ cannot withstand these USC and A-USC service conditions due to their quick oxidation and destruction. Currently, particular attention is focused on the austenitic steels with a high $\mathrm{Cr}$ content $(>20$ wt.\%), such as 310 stainless steel (310SS) or more advanced with higher $\mathrm{Ni}$ contents, like Incoloy, where adequate mechanical properties are combined with high-temperature corrosion resistance owing to the formation of continuous, thin, adherent, thermally grown oxide $\mathrm{Cr}_{2} \mathrm{O}_{3}$ and/or spinel-type scale, depending on metal composition (Ref 3-6). Nevertheless, under longterm exposure, even 310SS and other $\mathrm{Cr}$ - and Ni-rich steels and alloys experience degradation due to breakaway oxidation (Ref 7-11).

Therefore, it is important to develop the coating systems, which can protect high $\mathrm{Cr}$ and $\mathrm{Ni}$ steels and alloys against breakaway oxidation. In particular, the coating technology should be applicable for the formation of the protective layers on the inner or inner and outer surfaces of large size and complex shape components, e.g., long-size tubing. In this regard, many coating technologies (e.g., cold and thermal spray coatings, physical vapor deposition, electrophoretic deposition) have a limitation. As one of the prospective protective hightemperature coating options, the aluminized coatings can be considered (Ref 12, 13). These coatings usually consist of two or more layers of aluminides (e.g., $\mathrm{Fe}, \mathrm{Cr}$, Ni-aluminides) with different $\mathrm{Al}$ contents, and they can withstand high-temperature corrosion environments to protect steels (Ref 14-22). They can be produced according to the thermal diffusion technology. This surface engineering technology, which is also called as "thermochemical processing," diffusion coating process," "pack cementation," is based on the CVD principles (Ref 17-26) and is applicable for industrial large-size products. In addition, it would be reasonable to consider the coatings with more complex architectures (i.e., with more protective layers), since, according to the recent studies (Ref 27-32), such composite structures have also high potential in corrosion applications. 
The evaluation of the materials for high-temperature oxidation, in general, requires substantial time, especially for the alloys with high contents of $\mathrm{Ni}, \mathrm{Cr}$ and some other metallic ingredients and for the coated steels and alloys. Thus, the longtime testing for 2000-3000 h or longer, up to $10,000 \mathrm{~h}$, will provide reliable results and appropriate understanding of the material performance. However, in order to obtain preliminary data with regard to the possibility of the coatings for hightemperature application, the principles of the thermal gravimetric analysis (TGA) and the related instrumentation may be applied. In this case, the materials testing and the "screening" selecting the probabilities would be rather quick. Hence, in the present work, a few different coating structures (architectures) based on the intermetallide phases in the Fe-Al, Cr-Al, Ni-Al systems deposited on $310 \mathrm{SS}$ and $800 \mathrm{H}$ Incoloy through the thermal diffusion process have been prepared, and they have been exposed at $1000{ }^{\circ} \mathrm{C}$ for $8 \mathrm{~h}$ using thermogravimetric balance with consequent examination to predict their steam oxidation performance. These studies could be helpful for understanding of only the first stage of high-temperature oxidation of materials since the testing time is short.

\section{Experimental Procedure}

\subsection{Starting Materials and Coatings Deposition Process}

Stainless steel 310 grade (310SS) and Incoloy $800 \mathrm{H}$ produced by Sandvik Materials Technology and ThyssenKrupp VDM and supplied by Rolled Alloys (Canada) have been selected for the study. Table 1 shows chemical compositions of these starting materials according to the provided mill test report (MTR) certificates. The materials have been treated using a 600-grit SiC paper and ultrasonically cleaned with acetone for $15 \mathrm{~min}$.

For the coating formation, the samples were processed according to the proprietary aluminizing technology (EndurAlon $^{\mathrm{TM}}$ ) of Endurance Technologies Inc. (ETI). This technology is one of the options of thermal diffusion processing or pack cementation. The steel samples cleaned from a grease and a scale, as described above, have been placed in a special retort contained a special aluminized mix. This mix contained an Al-rich donor, a halide salt used as an activator and inert filler; all materials were in the powder form. The mix formulation was developed by ETI, and particle size of the starting powders has been specially selected providing easy flow and compaction. The sealed retort with the aluminized mix and the samples has been heated in the temperature range of $850-1000{ }^{\circ} \mathrm{C}$ for a certain holding time period in an electric kiln. At heat treatment, the Al-rich gases are formed due to high-temperature reactions; the forming atoms of $\mathrm{Al}$ deposit onto the metallic substrate surface with consequent diffusion to the steel structure. Due to the inward diffusion of $\mathrm{Al}$ and outward diffusion of $\mathrm{Fe}, \mathrm{Cr}, \mathrm{Ni}$, the aluminides are formed with subsequent consolidation of the coating structure. After cooling of the kiln, the samples were removed from the processed powder and cleaned using a brush and acetone. In order to prepare the coatings with more "complex" architectures, an additional protective layer was applied onto the aluminized samples. To obtain that, the aluminized samples were immersed into the ceramic suspensions with nanoparticles of selected concentrations; the top layer deposition was conducted under pressure. These suspensions are based on ceramic materials with high oxidation resistance, e.g., based on the oxides of metals of III-IV group of the periodical table and BN, i.e., based on the materials with rather high degrees of covalent bonds and thermodynamic potentials. Thus, for the top coating, the ceramic slurries contained $\mathrm{Al}_{2} \mathrm{O}_{3}, \mathrm{SnO}_{2}, \mathrm{ZrO}_{2}(3 \mathrm{~mol} \%$ $\mathrm{Y}_{2} \mathrm{O}_{3}$ ) and $\mathrm{BN}$ have been utilized; the solid contents varied from $\sim 0.5$ to $30 \mathrm{wt} . \%$. The samples with applied coatings have been air-dried and then consolidated in an electric kiln at temperatures ranging $500-700{ }^{\circ} \mathrm{C}$. The types of the coatings are shown in Table 2. The approximate dimensions of the samples with coatings for oxidation corrosion evaluation were $1 \times 0.65 \times 0.5 \mathrm{~cm}$. The dimensions of the uncoated samples were smaller.

\subsection{Steam Oxidation Tests}

The samples with rectangular shapes with the above-noted dimensions have been tested using TGA STA 449 F1 Jupiter ${ }^{\circledR}$ NETZSCH Thermobalance at $1000{ }^{\circ} \mathrm{C}$ for $8 \mathrm{~h}$ in pure water steam atmosphere. This TGA unit and small alumina ceramic crucibles used for holding of the samples allow testing the samples with selected dimensions when practically a whole surface of the sample is under the action of the gas flow. A temperature profile for steam oxidation testing included heating up at the rate of $15{ }^{\circ} \mathrm{C} / \mathrm{min}$ followed by holding at the testing temperature. The water vapor was introduced into the furnace at $140{ }^{\circ} \mathrm{C}$ to avoid condensation. The water vapor flow was adjusted by a volume flow controller as $3 \mathrm{~g} / \mathrm{h}$ during the whole experiment. The steam liner velocity was equivalent to $5 \times 10^{-5} \mathrm{~m} / \mathrm{s}$ for $3 \mathrm{~g} / \mathrm{h}$ intensity of water vapor; this value represents to velocity in liner at the following testing parameters: temperature $140{ }^{\circ} \mathrm{C}$, pressure 1 bar and density of water vapor at $140{ }^{\circ} \mathrm{C}$ as $0.53 \mathrm{~kg} / \mathrm{m}^{3}$. Prior to the TGA run, the system has been cleaned to obtained consistent results. Thus, deionized water from the tank located underneath the thermogravimetric balance was transported throughout the heating transfer line. The heating transfer line with maximum operating temperature of $200{ }^{\circ} \mathrm{C}$ was set up for $180{ }^{\circ} \mathrm{C}$. The purging synthetic gas containing $80 \%$ vol. nitrogen and $20 \%$ vol. oxygen was initially connected to the system and ran for $2 \mathrm{~h}$ with the recommended $50 \mathrm{ml} / \mathrm{min}$ flow in order to clean the furnace from moisture and contaminants. Further, during the tests, a protective gas (Ar) was used with a $50 \mathrm{ml} / \mathrm{min}$ flow rate. The purge synthetic gas and a protective gas were not delivered and were not mixed with steam in the furnace; they were used only to clean and protect the balance underneath the steam furnace, ensuring the tests were performed in pure steam conditions. The post-process deionized water was returned to

Table 1 Chemical composition of the uncoated 310SS and 800H (wt.\%)

\begin{tabular}{llllllllllllll}
\hline & $\mathbf{F e}$ & $\mathbf{N i}$ & $\mathbf{C r}$ & $\mathbf{M o}$ & $\mathbf{S i}$ & $\mathbf{M n}$ & $\mathbf{N b}$ & $\mathbf{A l}$ & $\mathbf{C}$ & $\mathbf{P}$ & $\mathbf{S}$ & $\mathbf{T i}$ \\
\hline $310 \mathrm{SS}$ & Bal. & 20.11 & 24.51 & 0.42 & 1.5 & 1.25 & 0.01 & 0.005 & 0.043 & 0.022 & 0.0009 \\
$800 \mathrm{H}$ & 46.6 & 30.3 & 20.6 & $\ldots$ & 0.4 & 0.7 & $\cdots$ & 0.44 & 0.09 & $\ldots$ & $<0.002$ & 0.51 \\
\hline
\end{tabular}




$\begin{array}{lll}\text { 3A } & 8 \mathrm{~A} & \text { Aluminized steel } \\ \text { 3B } & 8 \mathrm{~B} & \text { Aluminized steel with } \mathrm{Al}_{2} \mathrm{O}_{3}-\text { based top layer } \\ \text { 3C } & 8 \mathrm{C} & \text { Aluminized steel with } \mathrm{SnO}_{2} \text { top layer } \\ \text { 3D } & 8 \mathrm{D} & \text { Aluminized steel with } \mathrm{ZrO}_{2} \text {-based top layer } \\ \text { 3E } & 8 \mathrm{E} & \text { Aluminized steel with } \mathrm{BN} \text { top layer }\end{array}$

Number 3 denotes $310 \mathrm{SS}$ and number 8 denotes $800 \mathrm{H}$

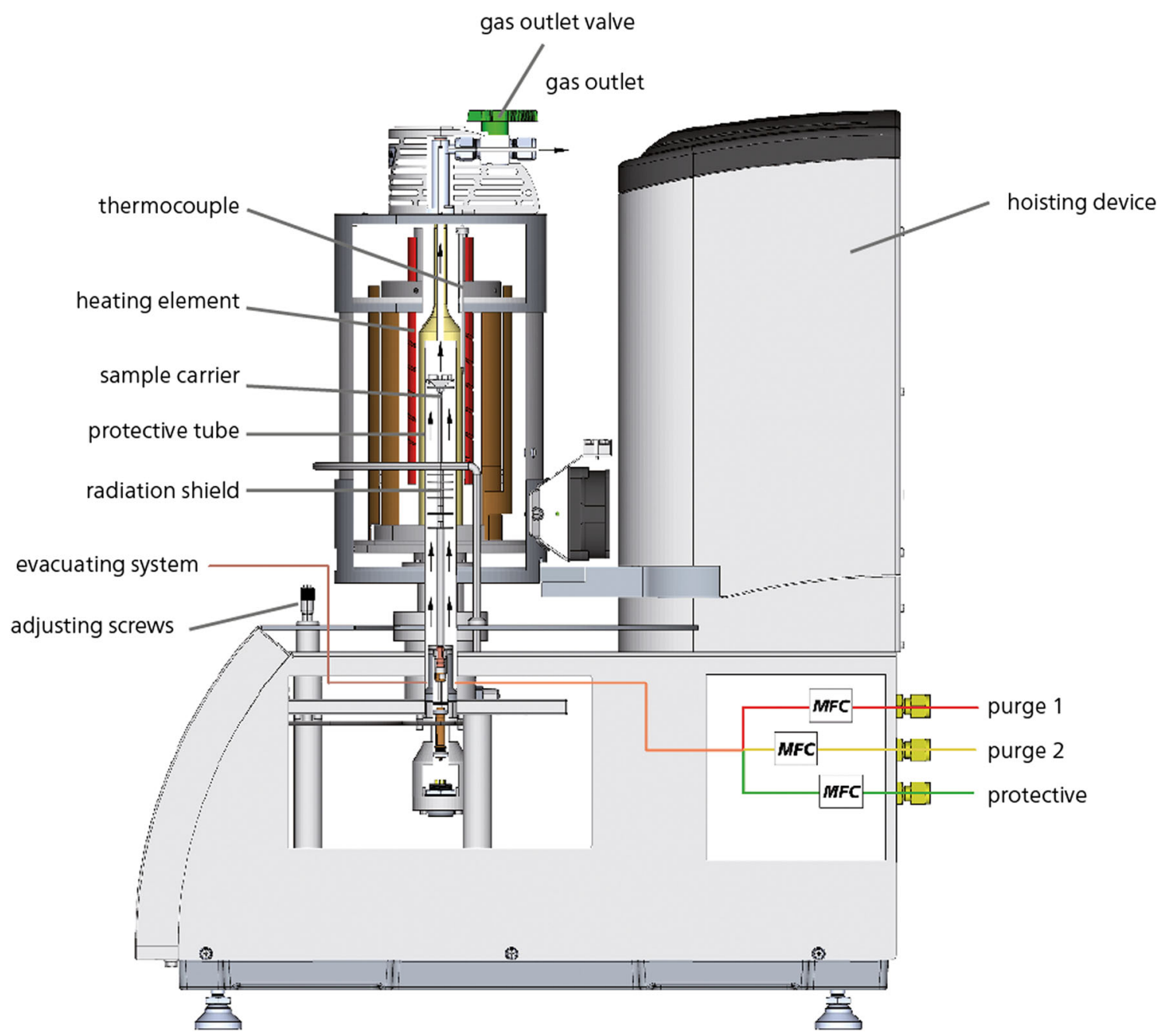

Fig. 1 Schematics of the TGA STA 449 F1 Jupiter ${ }^{\circledR}$-NETZSCH

the condenser to close the cycle. A schematic diagram representing the TGA equipment used in this work is shown in Fig. 1. During high-temperature tests, the graphs of weight changes [mg] of the exposed sample against time [h] were plotted automatically using Proteus 6.1 commercial software.

\subsection{Materials Examination}

The samples prior and after exposure have been examined from the surfaces using DSLR Canon EOS 70D camera coupled with Canon MP-E $65 \mathrm{~mm} \mathrm{f} / 2,8$ macro lens and with scanning electron microscope (SEM) Hitachi TM3000 coupled with Bruker energy x-ray dispersive spectrometry (EDS) for chemical composition evaluation. The SEM examination for the surface morphology (before and after oxidation testing) was conducted in the backscatter electron (BSE) mode under $15 \mathrm{kV}$ accelerated voltage. The examination of the cross sections has been performed with light optical microscope MEIJI Techno 1M7200 to observe possible changes of the coating structures. For the samples preparation for the cross-section microscopy examination, precision cutting-polishing procedure established at ETI has been employed using the Buehler equipment. The special etching composition has been selected to reveal the structural features in the cross sections. Micro-hardness deter- 

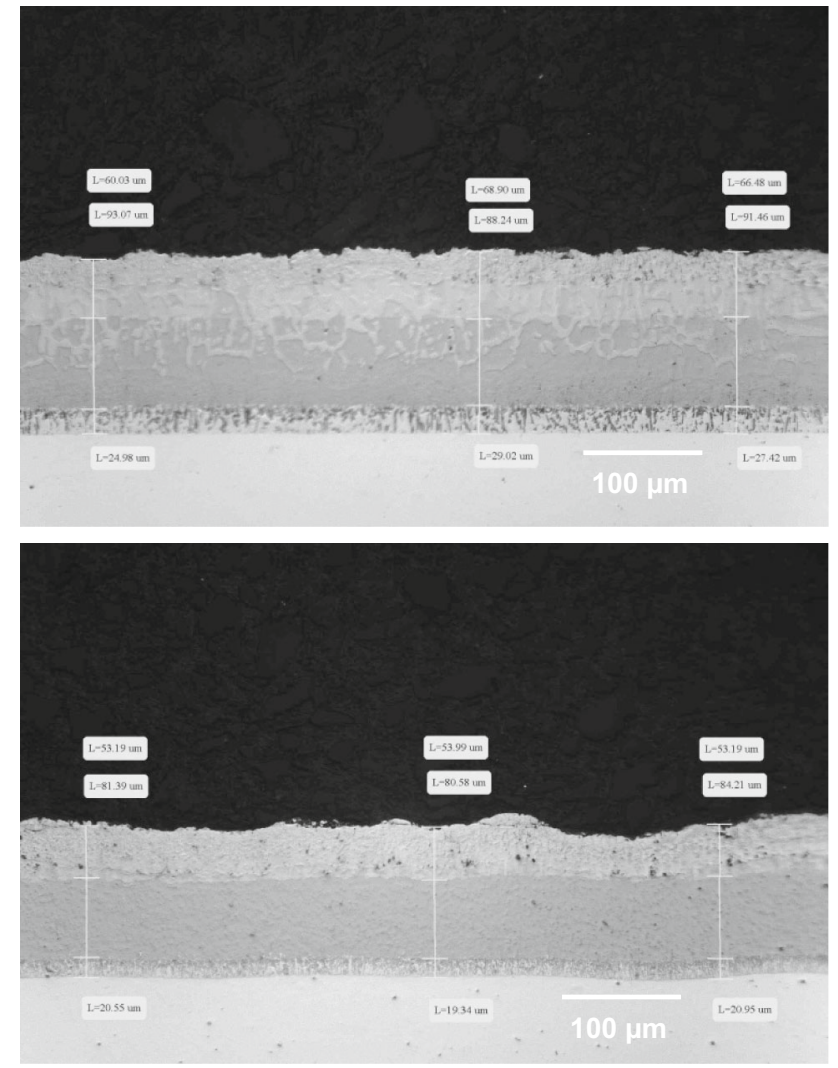

Fig. 2 Microstructures (cross sections) of the aluminized 310SS and $800 \mathrm{H}$ (coatings $3 \mathrm{~A}$ - top and $8 \mathrm{~A}$ - bottom, respectively)

mination of the aluminized coating layers has been conducted according to the ASTM E384-10 using the tester Clark CM 400AT with the Knoop diamond indenter at the indentation load of $100 \mathrm{~g}$ (HK0.1) applied to the cross section of polished samples under microscope.

\section{Results and Discussion}

\subsection{Evaluation of the Coating Structures Before TGA Oxidation Testing}

The aluminized samples obtained on $310 \mathrm{SS}$ and $800 \mathrm{H}$ have the multilayer structures (architectures) formed by three aluminized layers with different contents of $\mathrm{Al}$, which are defined by the high-temperature diffusion process. The layer over the substrate called as the "transition" layer contains about 4-7 wt.\% of $\mathrm{Al}$, and it is enriched with $\mathrm{Fe}, \mathrm{Ni}$ and $\mathrm{Cr}$. The next layer is the "main aluminized layer" with a content of $\mathrm{Al}$ of 32-38 wt.\%, and the top aluminized layer is the "Al rich" with a content of $\mathrm{Al} \sim 44-50$ wt.\%. The contents of $\mathrm{Fe}, \mathrm{Ni}$ and $\mathrm{Cr}$ are lower accordingly. The contents of the main elements in the coating are defined by the inward diffusion of $\mathrm{Al}$ and outward diffusion of the main elements from the metallic substrate and by the formation of aluminides $\mathrm{Fe}(\mathrm{Cr}, \mathrm{Ni})_{x} \mathrm{Al}_{y}$. A total case depth of the aluminized material and a thickness of each layer and its chemistry are defined by the composition of the substrate material, by the composition of the aluminizing mix and by the process parameters, e.g., substrate surface preparation, temperature, time and some other features of heat treatment and related gas formation, which affect deposition and diffusion of the elements during the process. The total case depths of the aluminized 310SS and $800 \mathrm{H}$ are $\sim 170-190 \mu \mathrm{m}$ and $\sim 150-170 \mu \mathrm{m}$, respectively. The thicknesses of the main layer and the Al-rich top layer are $\sim 85-95$ and $\sim 60-70 \mu \mathrm{m}$ for aluminized $310 \mathrm{SS}$ and $\sim 77-82$ and $\sim 55-70 \mu \mathrm{m}$ for aluminized $800 \mathrm{H}$, respectively, i.e., the thicknesses of the two coating layers, which provide corrosion protection, are $\sim 150$ $165 \mu \mathrm{m}$ and $\sim 135-150 \mu \mathrm{m}$ for aluminized $310 \mathrm{SS}$ and $800 \mathrm{H}$, respectively. Accordingly, the thickness of the transition layer for aluminized $310 \mathrm{SS}$ is $\sim 25-30 \mu \mathrm{m}$, while a thickness of this layer in the case of $800 \mathrm{H}$ is slightly lower $(\sim 17-22 \mu \mathrm{m})$. The images of the microstructures (cross section) of the aluminized $310 \mathrm{SS}$ and $800 \mathrm{H}$ (coatings $3 \mathrm{~A}$ and $8 \mathrm{~A}$, respectively) obtained with light optical microscope are shown in Fig. 2. The interface between the layers is not very clear that is dealt with the diffusion process. Due to the established process at ETI, the structure is well consolidated, and no Kirkendall porosity is observed. Comparing the considered structure with structures of many other aluminized coatings reported in the literature, the presented coating features by two protective layers well consolidated despite their sufficient thickness.

The top layers obtained through the deposition of the suspensions with nanoparticles onto the aluminized steel have thicknesses from below $1 \mu \mathrm{m}$ (for the coatings $3 \mathrm{E}$ and $8 \mathrm{E}$ based on $\mathrm{BN}$ ) to a few microns (for the coatings $3 \mathrm{~B}-3 \mathrm{D}$ and $8 \mathrm{~B}-8 \mathrm{D}$ based on oxides). The thickness of these layers depends on solid concentration in the suspensions, size of nanoparticles and duration of deposition. The surface morphologies would be shown and are discussed in section 3.4.

\subsection{Evaluation of High-Temperature Oxidation: Appearance}

The appearance of the samples, prior to the TGA oxidation testing, is shown in Fig. 3(a), (b), (c), (d) and (e) (310SS substrate) and Fig. 4(a), (b), (c), (d) and (e) (800H substrate), respectively. They have no spallation, cracks, delamination or any other visible defects. Small spots on some samples can be observed, and these spots with local color deviations on the surface may be related to uneven thickness of the top coatings (which were applied by a dipping technique) and imperfect surface of the aluminized samples, on which these top layers were applied. The appearance of the samples after the TGA steam exposure can be seen in Fig. 5(a), (b), (c), (d) and (e) and 6(a), (b), (c), (d) and (e), respectively. The coated samples after the TGA test have only a small degree of surface change with no visible cracking, pitting, delamination, etc. Only some discoloration was observed, and the samples became smoother. Small peeling of the top oxide "skin" from the samples 3B, 3C and $8 \mathrm{D}$ can be noted. The bare $310 \mathrm{SS}$ sample also did not have visible changes of the surface, while visible spalling of the oxidized surface could be seen in some areas of the bare $800 \mathrm{H}$ sample (Fig. 6e).

\subsection{Evaluation of High-Temperature Oxidation: Kinetics of Oxidation}

The graphs of the mass change versus time obtained directly from the TGA instrumentation conducted at high temperatures of $1000{ }^{\circ} \mathrm{C}$ (Fig. 7, 8) show the kinetics of oxidation of the studied samples. Since the samples had different original masses and surface areas, the absolute mass change recorded directly from the TGA unit cannot be 


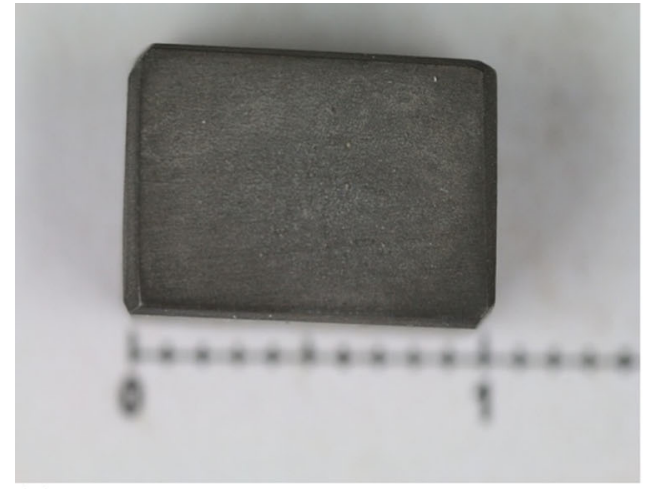

(a)

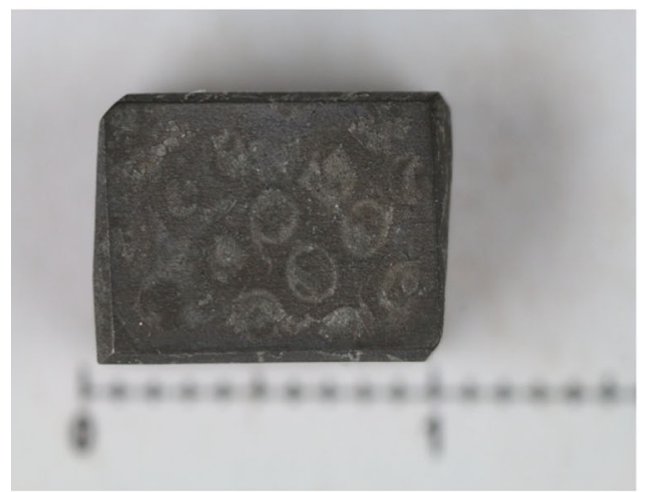

(c)

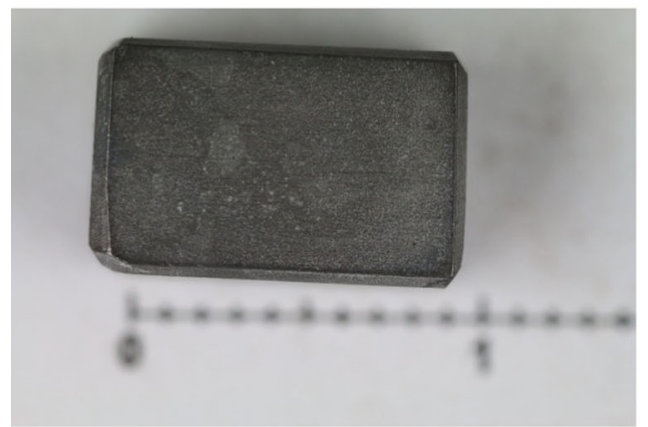

(e)

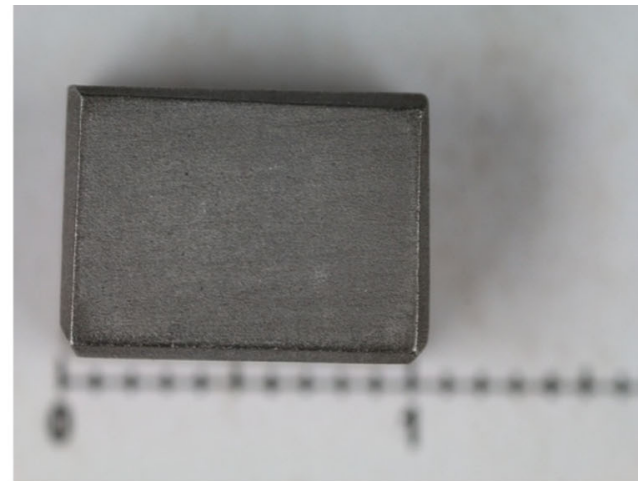

(b)

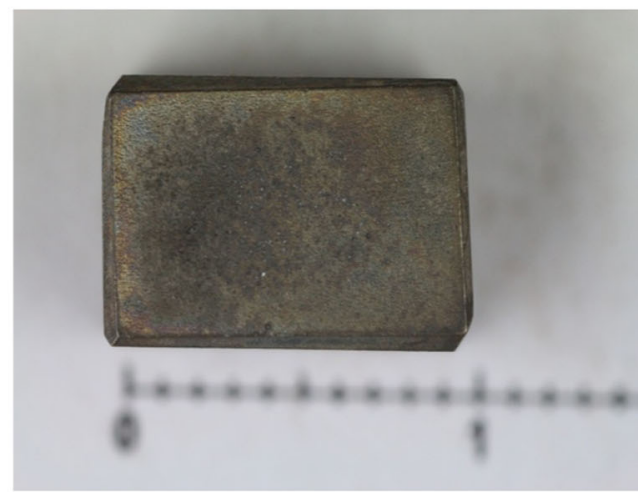

(d)

Fig. 3 Appearance of the coated samples prior steam oxidation tests (310SS substrate)

considered as the right criterion of the material behavior during oxidation, but the trend of the mass change versus time may be valuable for understanding of the oxidation behavior. The shape of the graphs (curves) depends on the composition and structure of the surfaces of the samples and the processes occurring on the surface at oxidation; however, all these graphs have three "segments" with different mass changes during oxidation time.

As can be seen in Fig. 7 and 8, as well as in Fig. 9 that shows all these curves combined together, all samples experienced mass reduction at the first $0.25-0.5 \mathrm{~h}$ of the heating; then, the mass gain rapidly occurred (during the second $0.5 \mathrm{~h}$ of the heating), and finally, the mass gain occurred slower during the soak at the $1000{ }^{\circ} \mathrm{C}$. According to the works (Ref 8, 33), the first segment related to the initial period of exposure can be called as the "transient oxidation" or "pre-steady state oxidation" segment. The observed small mass reduction in the samples at this segment may be explained by instability during the heating and fluctuations in the gas flow during this period, in particular when the steam is introduced at $140{ }^{\circ} \mathrm{C}$. This gas flow may affect the behavior of the microbalances of the TGA instrumentation leading to small deviations on the curves. Also this mass reduction effect may be dealt with the absorption of steam on the surface of the samples due to their roughness (before and during the first minutes of heating) and the consequent evaporation of steam at higher temperatures. The behavior of this graph with the mass reduction during the first segment is similar to the graphs indicating the behavior of Ni-based alloys at the initial oxidation stages described in the recent work (Ref 34). Comparing the mass loss for the studied samples at the first segment, it can be seen that the highest mass loss $(\sim 0.9 \mathrm{mg})$ is observed for the sample 3A (aluminized $310 \mathrm{SS}$ ) with higher surface roughness than the samples with the top coatings and bare (uncoated) metals (0.15-0.4 mg). 


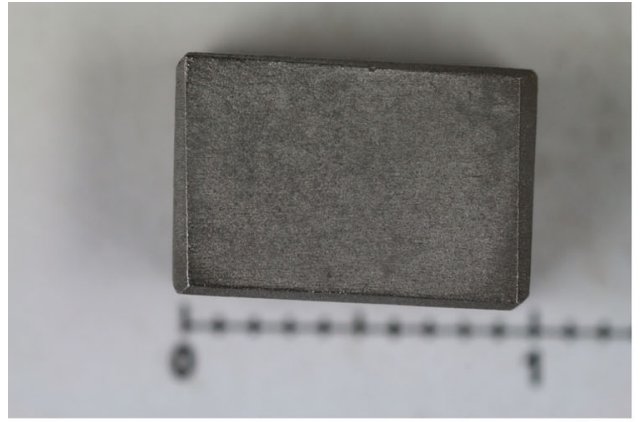

(a)

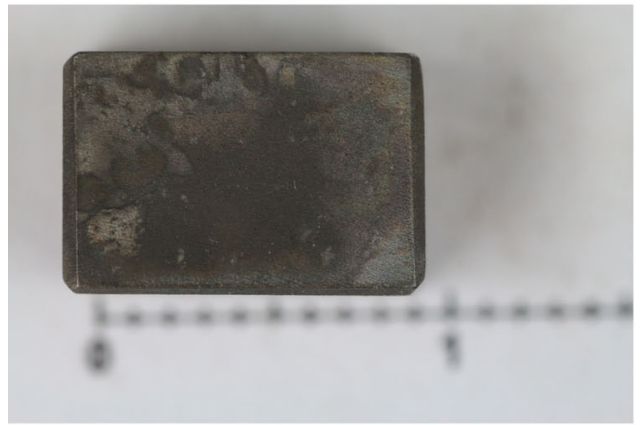

(c)

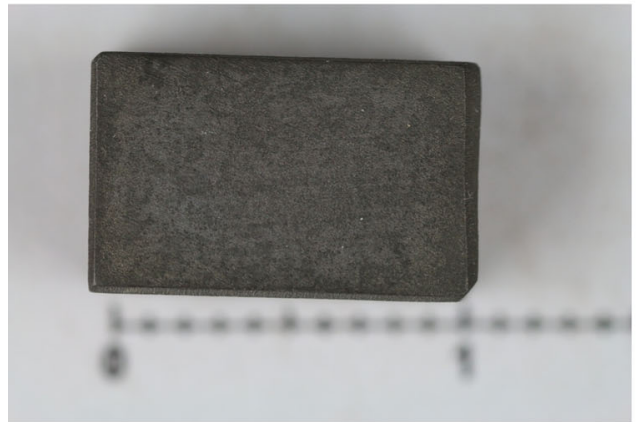

(e)

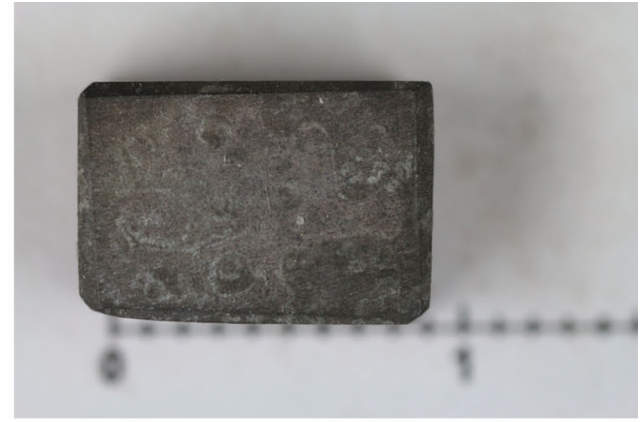

(b)

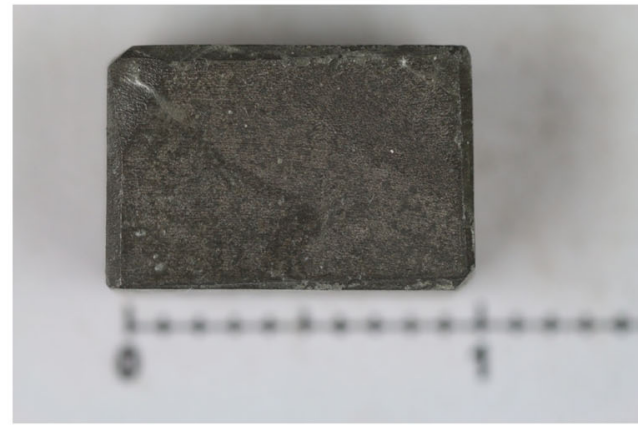

(d)

Fig. 4 Appearance of the coated samples prior steam oxidation tests $(800 \mathrm{H}$ substrate $)$

Then, at the second and third segments of the kinetic curves, for some samples ( $3 \mathrm{~A}$ and $3 \mathrm{~F}-8 \mathrm{~F}$ ), the mass gain occurred rather gradually, while for other samples (particularly 3B-D, 8B-E), the mass gain occurs quickly; for some coated samples, the mass gain reaches almost constant values approaching the "plateau." It may be expected that similar "plateau" in the mass gain may be reached also for other samples with aluminized coatings (without and with an additional top layer) if longer high-temperature soaks are applied.

As can be seen from these graphs, their mass change behavior versus time deviates from the parabolic curves, and this is rather common for the initial stage of high-temperature oxidation (Ref 34), i.e., the "initial" stage of high-temperature oxidation has not been completed yet. The observed behavior of the mass gain can be explained by the interaction of the surfaces with oxygen and by the formation of the oxide layers and their growth and consolidation, which depends, as mentioned above, on the samples surface compositions and coating architectures. The formation and growth of the thermodynamically stable oxide scale (layer), e.g., the alumina-based layer for the studied samples with the aluminized coatings, can be considered as a positive point. The presence of the additional thin layer on the top of the aluminized layer in the coating architecture may reduce the further oxidation process of the aluminides that is correlated with a curves' behavior. It is related to not only thermodynamically stable oxides, like $\mathrm{Al}_{2} \mathrm{O}_{3}, \mathrm{SnO}_{2}$ and $\mathrm{ZrO}_{2}$, but also $\mathrm{BN}$ that had extremely small thickness (a submicron range that was not easy determined).

\subsection{Evaluation of High-Temperature Oxidation: Surface Morphology, Structure and Hardness}

The surface morphology images studied with SEM in the BSE mode for the samples before and after TGA steam oxidation can be seen in Fig. 10-14. The samples with only aluminized coating ( $3 \mathrm{~A}$ and $8 \mathrm{~A}$ ) and with aluminized coating and a very thin $\mathrm{BN}$ top layer ( $3 \mathrm{E}$ and $8 \mathrm{E}$ ) have more even surfaces, while the aluminized samples with oxide top layers (3B and 8B, 3D and 8D) have less homogeneity with an appearance of surface micro-cracks. Some deviations from even surface (e.g., small spots) of the aluminized samples and the 


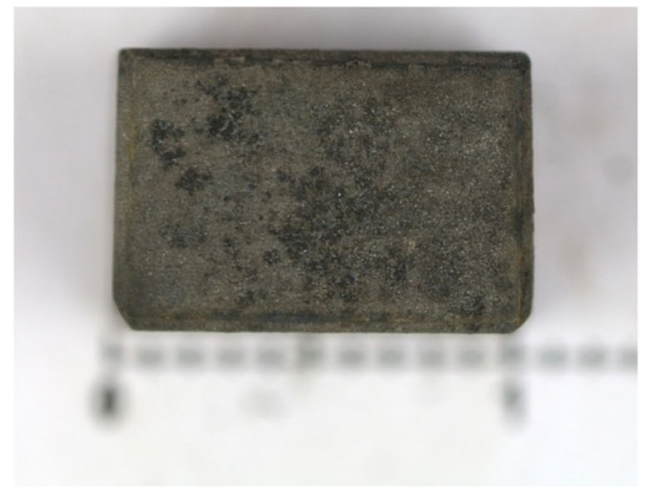

(a)

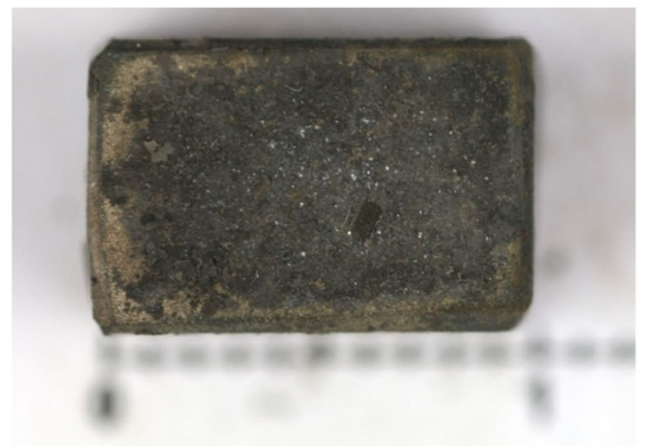

(c)

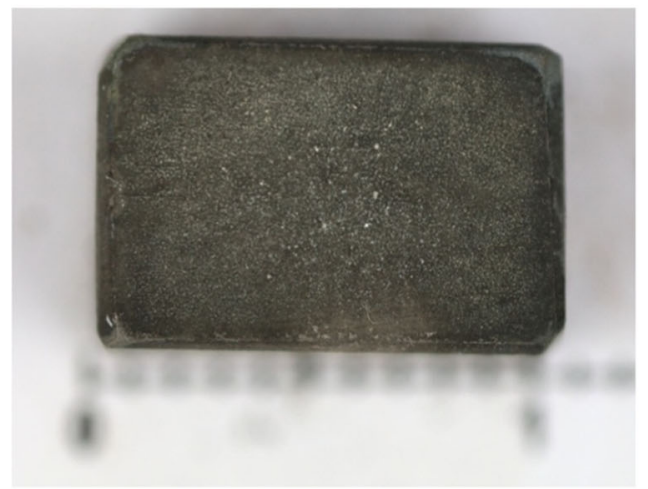

(e)

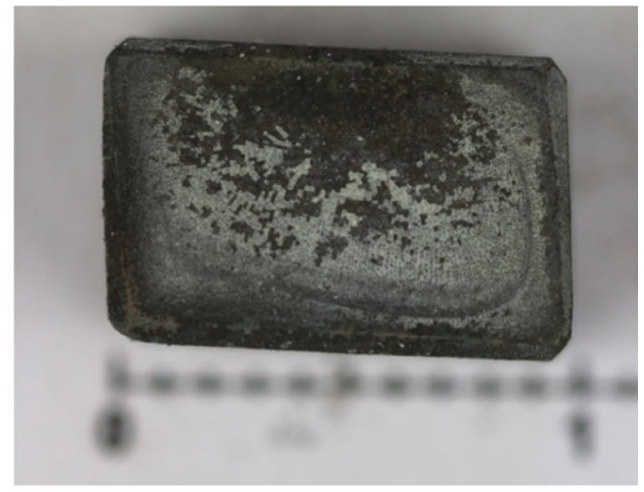

(b)

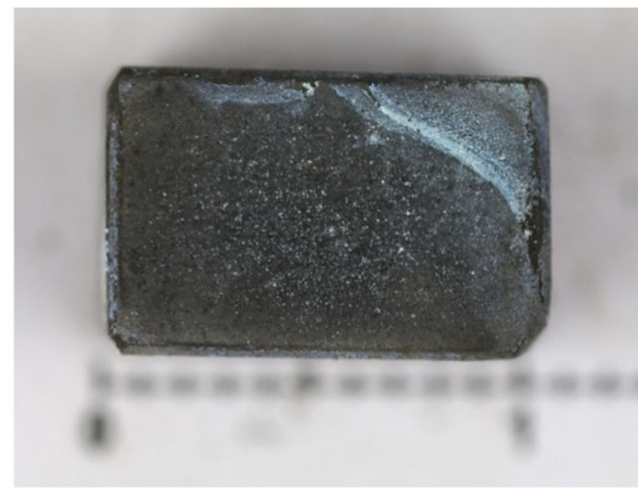

(d)

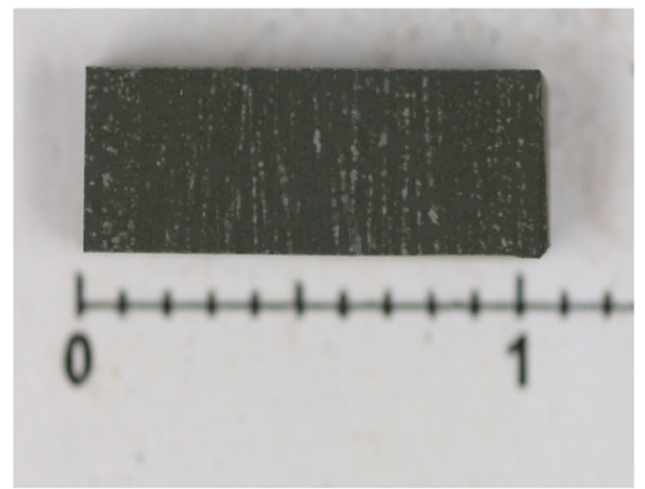

(f)

Fig. 5 Appearance of the samples after TGA steam oxidation: (a-e) coated 310SS, (f) uncoated 310S

samples with top $\mathrm{BN}$ layer are probably related to uneven morphology and thickness of the Al-rich layer and uneven pore distribution on this surface. For the samples with the top oxide layers, which thicknesses vary from below than $1 \mu \mathrm{m}$ to several $\mu \mathrm{m}$, the presence of the "egg-shell" surface micro-cracks observed is probably dealt with the adhesion issue occurred at thermal treatment after the top oxide layer deposition, e.g., with a coefficient of thermal expansion mismatch of the oxide layers and the aluminized steel. In addition, the tensile stresses occurred in the top coating layer during its consolidation at the heat treatment. However, these surface micro-cracks are well visible only at high magnifications $(750-1000 \times$ or greater); their width is rather small, below $1 \mu \mathrm{m}$, in particular, ranging from 70 to $300 \mathrm{~nm}$ (depending on the oxide layer composition), and their depth is also below $1 \mu \mathrm{m}$. The top oxide coatings have dense structures without visible pits and pores. The examples of their structures (e.g., top $\mathrm{Al}_{2} \mathrm{O}_{3}-, \mathrm{SnO}_{2}-$ and $\mathrm{ZrO}_{2^{-}}$ based coatings) under higher magnification $(2000 \times)$ can be seen in Fig. 12. It can be noted that the SEM images of the coated samples were made from not the "best" areas to demonstrate possible imperfectness. It has to be mentioned that, because the precision diamond saw was not used for the cutting of the samples for the SEM and EDS analyses, some areas of the top layer were broken off. Because of that, the underneath layers could be seen as "islands" on the SEM images.

After TGA oxidation, the SEM study showed only insignificant changes of the surfaces of the coated samples (Fig. 13, 14). The observed changes can be dealt, first of all, with oxidation of the aluminides leading to the formation of the chemically inert layer of $\mathrm{Al}_{2} \mathrm{O}_{3}$ and other oxides and its consolidation. Thus, according to results of the EDS analysis of the surfaces, which are presented for the selected samples in 


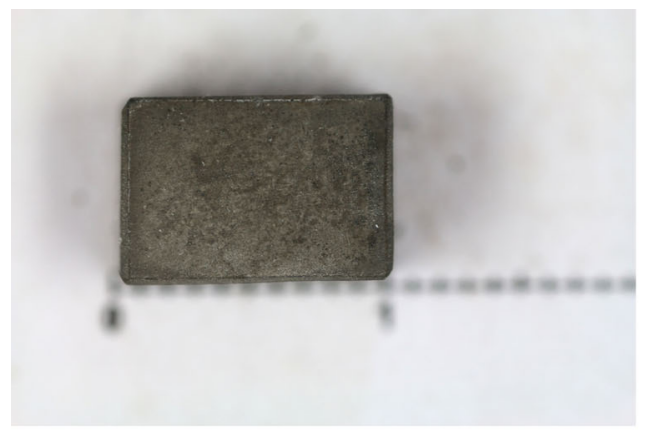

(a)
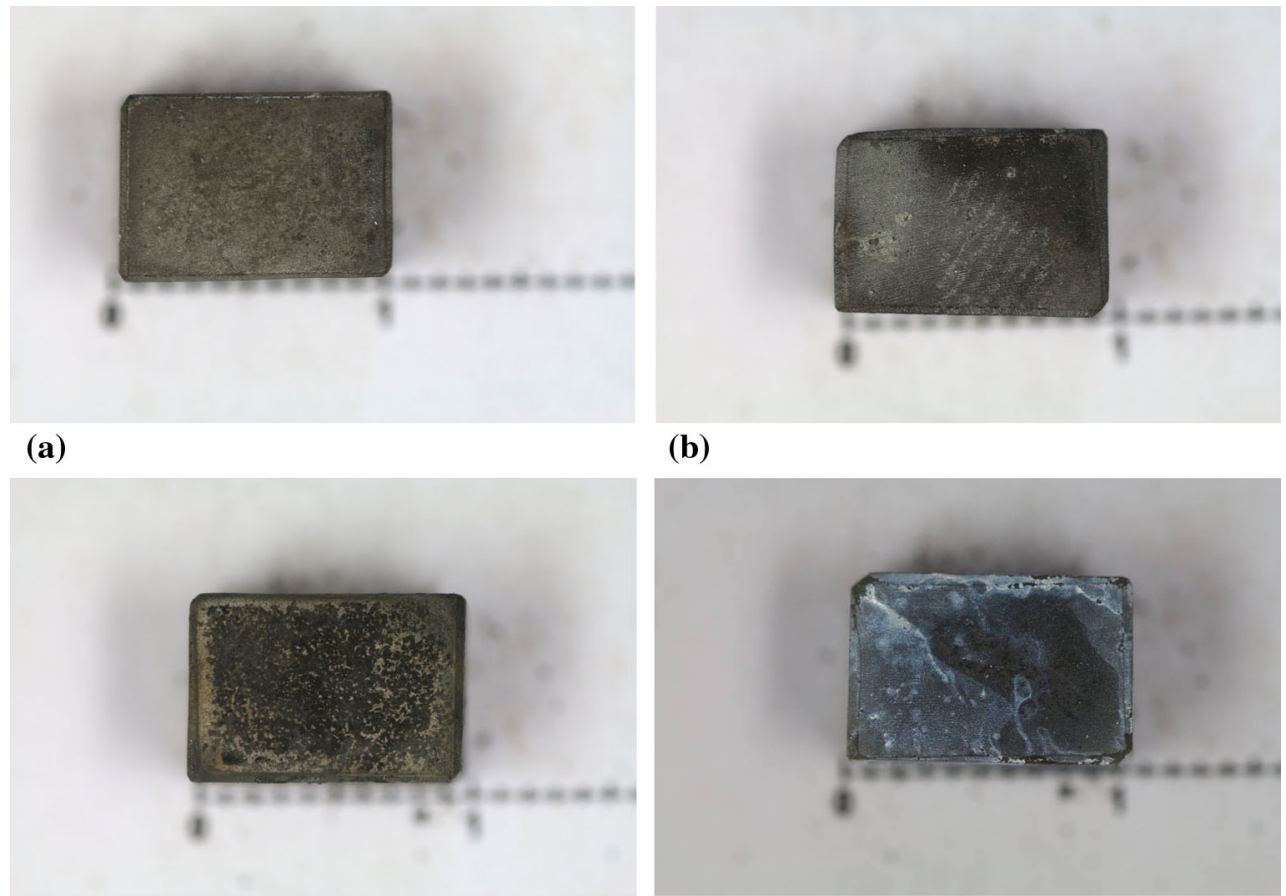

(b)

(c)
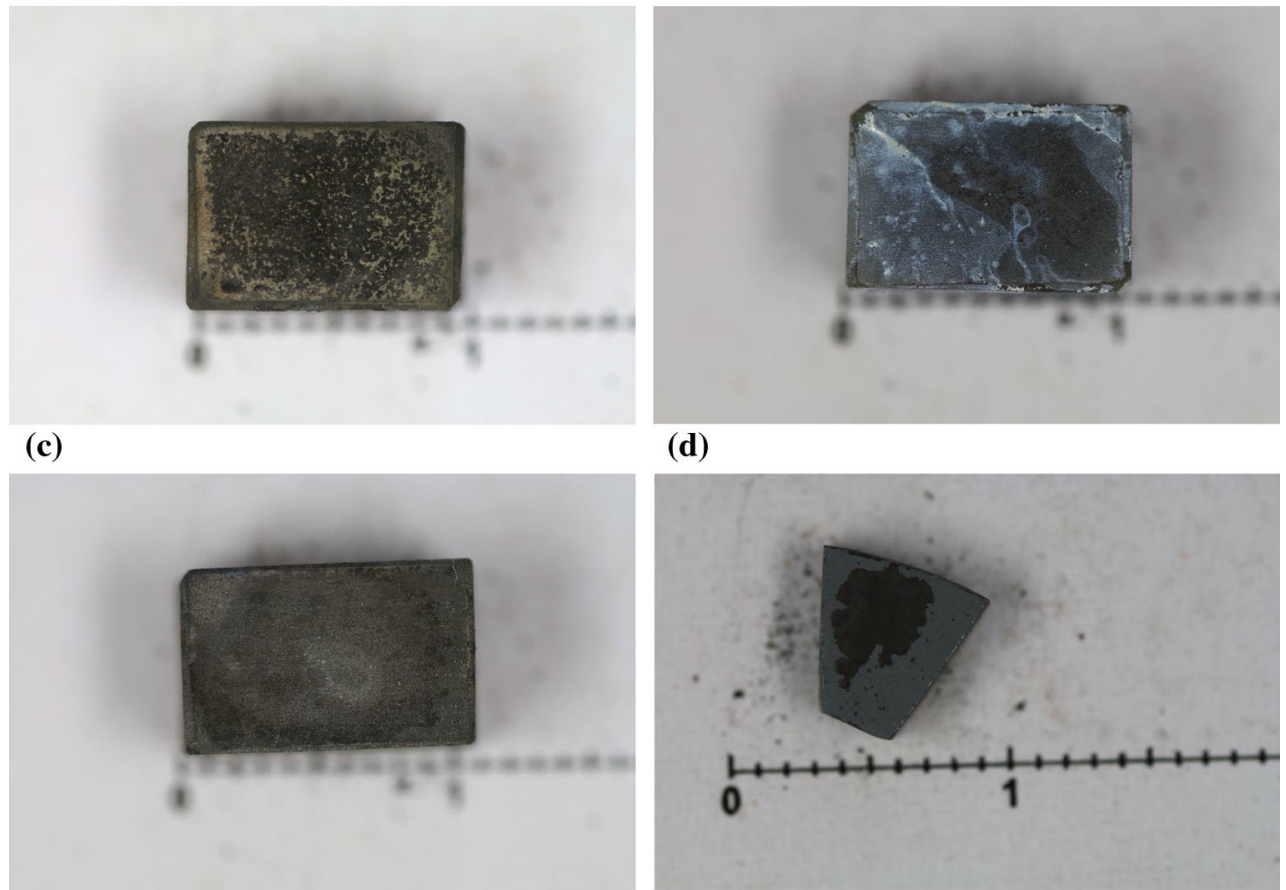

(d)

(e)

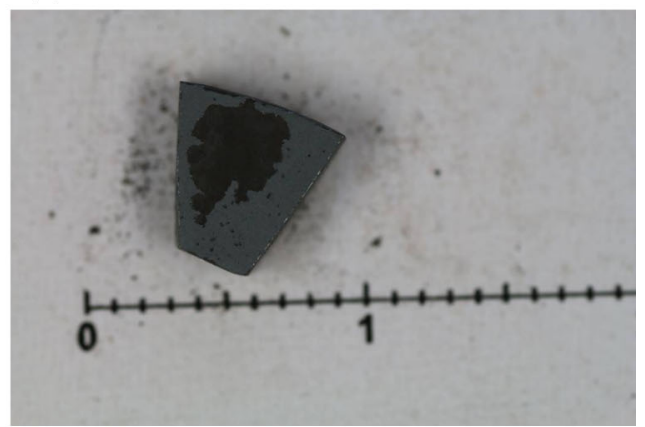

(f)

Fig. 6 Appearance of the samples after TGA steam oxidation: (a-e) coated $800 \mathrm{H}$, (f) uncoated $800 \mathrm{H}$ steel

Table 3 (the contents of only the major elements are presented), the oxygen contents reached $25-45$ wt. $\%$ or even greater depending on the type of the coating. This surface oxidation may be considered as a positive factor since all these oxides, in particular $\mathrm{Al}_{2} \mathrm{O}_{3}$, are stable at high temperatures. In the case of samples $3 \mathrm{~B}$ and $3 \mathrm{C}$ (Fig. 13b, c), some surface detachment of the external oxide layer $\left(\mathrm{Al}_{2} \mathrm{O}_{3}\right.$-based and $\mathrm{SnO}_{2}$ top layers $)$ was observed. The detachment and breakage of the top layer may be explained, as noted above, by not very accurate cutting of the samples for the SEM surface examination (the precision cutting saw with diamond tooling was not used). This detachment also may be invoked by incoherency of this top layer and the forming oxidation film, although the $\mathrm{SnO}_{2}$ top layer indicated better adhesion to the base aluminized coating layer (sample 3C) than that observed in the case of the sample 3B. The aluminized steel with the $\mathrm{ZrO}_{2}$-based top layer presented in Fig. 13(d) and 14(d) remained the "egg-shell" micro-cracking after oxidation although the width of these micro-cracks became smaller. The reduction in the surface micro-cracks after oxidation, i.e., their healing, is observed for all aluminized samples with the top oxide layer but to a different extent. The oxidation between the micro-cracks promotes the healing effect. Finally, the aluminized steel with the BN top layer in Fig. 13(e) and 14(e), which did not have surface micro-cracks, did not experience significant influence of high-temperature steam oxidation atmosphere, although, as mentioned above, the oxidizing film appeared with the color change. The discoloration for the samples has mainly only a superficial character. The key point of the performance of the coated samples is the appropriate adhesion of the oxidizing film with the aluminized layer.

In comparison with the coated samples, the uncoated 310SS and $800 \mathrm{H}$ experienced the formation of the scales with spots across the samples (Fig. 13f). Comparing these two materials, the uncoated $800 \mathrm{H}$ had significantly fewer spots, but it experienced a slightly delaminated structure of the oxidized surface (Fig. 14f). Also some pinholes (nodules) and surface micro-cracks can be seen on the oxidized 310SS (Fig. 13g).

Although some deviations of the surfaces of the coated samples after the TGA oxidation testing could be observed, the examination of the cross sections under light optical microscope did not find noticeable changes in the coating integrity after the oxidation according to Fig. 15(a), (b), (c), (d), (e) and (f) (coated 310SS) and Fig. 16(a), (b), (c), (d), (e) and (f) 


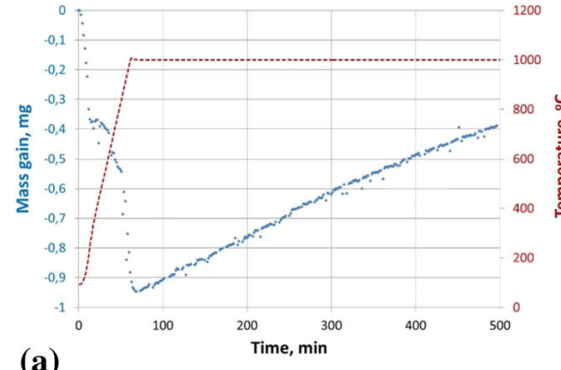

(a)

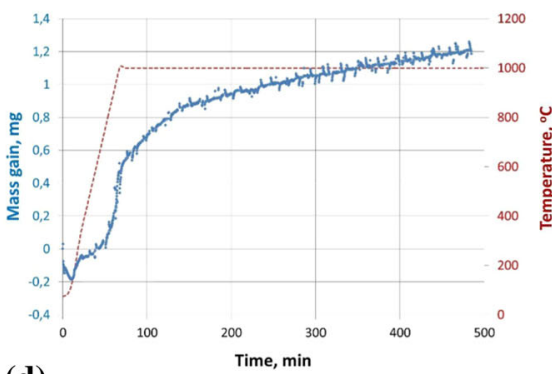

(d)

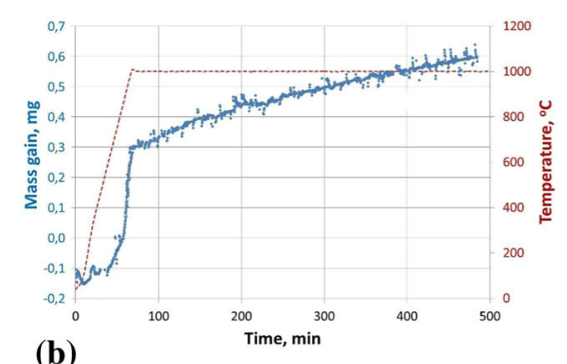

(b)

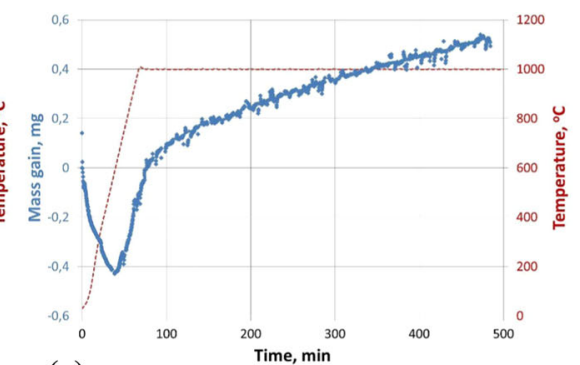

(e)

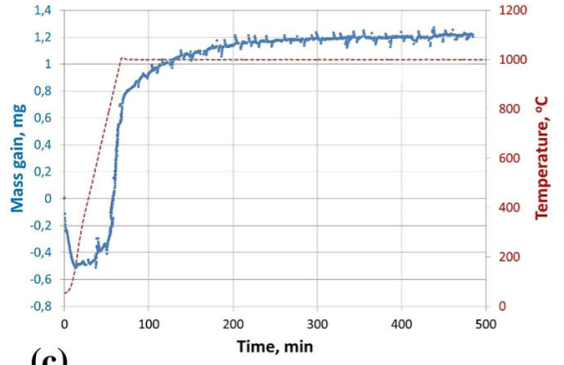

(c)

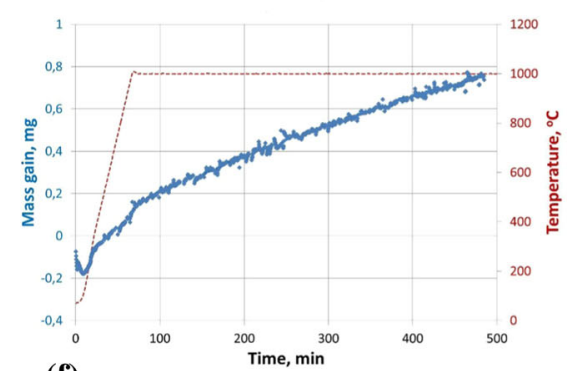

(f)

Fig. 7 Kinetic data for 3A-E coating systems and uncoated $310 \mathrm{SS}(3 \mathrm{~F})$ exposed at $1000{ }^{\circ} \mathrm{C}$ for $8 \mathrm{~h}$

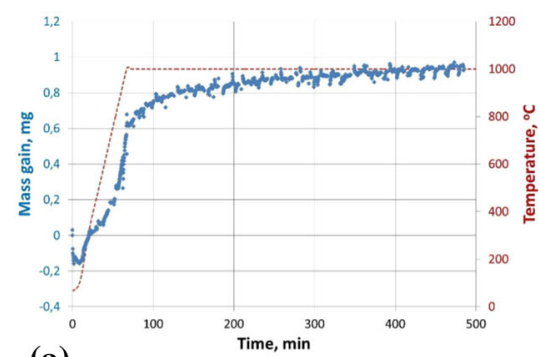

(a)

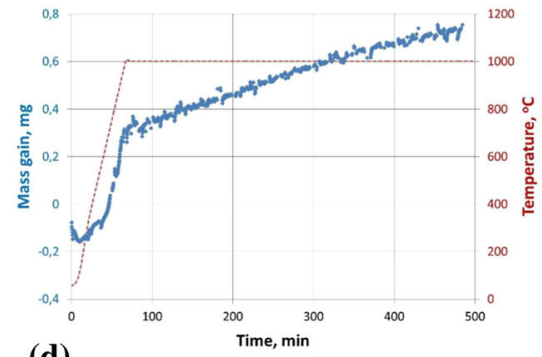

(d)

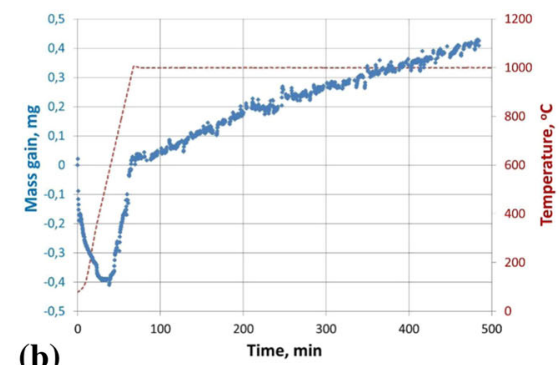

(b)

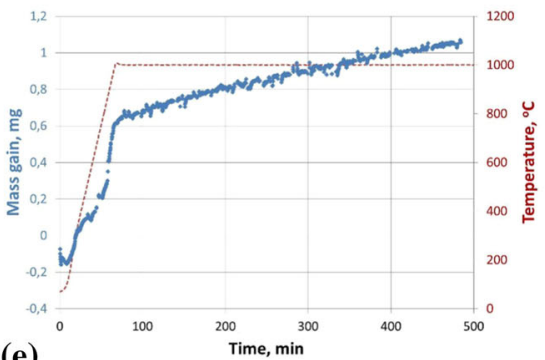

(e)
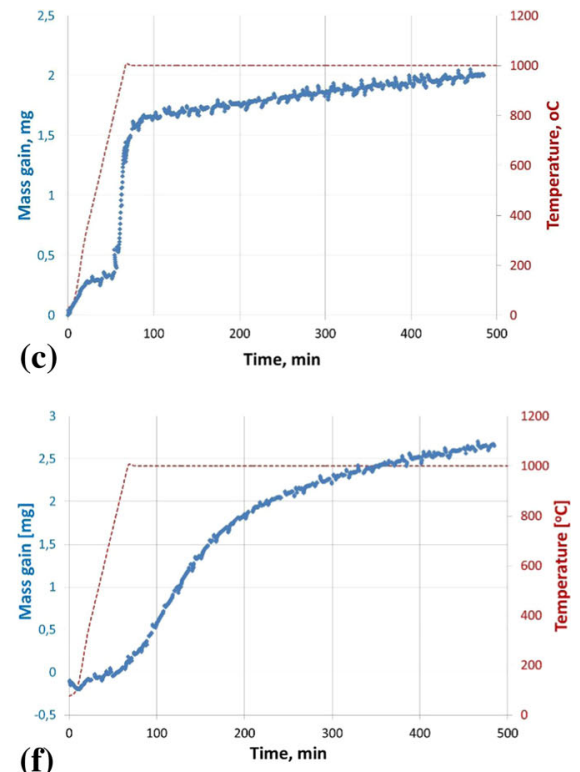

Fig. 8 Kinetic data for $8 \mathrm{~A}-\mathrm{E}$ coating systems and uncoated $800 \mathrm{H}(8 \mathrm{~F})$ exposed at $1000{ }^{\circ} \mathrm{C}$ for $8 \mathrm{~h}$

(coated $800 \mathrm{H}$ ). No visible coating destruction, delamination or pitting were observed. It is interesting to note that the total case depth increased after the high-temperature oxidation exposure. Also the Al-rich layer of the aluminized coatings practically disappeared for the aluminized 310SS samples, while this Alrich layer became smaller for the aluminized $800 \mathrm{H}$ samples $(20-30 \mu \mathrm{m})$. However, the main aluminized zone, as well as the thickness of the transition zone, became greater for all samples. Thus, for the original samples made from $310 \mathrm{SS}$ and $800 \mathrm{H}$, the transition zones were $\sim 25-30$ and $17-22 \mu \mathrm{m}$, respectively (Fig. 2), and, after the TGA testing, they became $\sim 70-80$ and $\sim 38-44 \mu \mathrm{m}$ (Fig. 7a, b, c, d, e). Accordingly, after the testing, the main aluminized layer, which, in fact, provides corrosion protection, grew up to $170-180 \mu \mathrm{m}$ in the case of the $3100 \mathrm{SS}$ substrate. In the case of aluminized $800 \mathrm{H}$ samples, a size of the total protective layer became slightly greater reached 145-160 $\mu \mathrm{m}$ (increased the main aluminized layer and reduced the Al-rich layer). This growth can be explained by the continuation of the diffusion processes at the high testing temperature. In fact, the testing temperature $\left(1000{ }^{\circ} \mathrm{C}\right)$ and the soak time $(8 \mathrm{~h})$ were greater or about the same compared to the aluminizing process parameters. Thus, at applied testing temperature, the inward diffusion of $\mathrm{Al}$ continued from the Al-rich zone, and $\mathrm{Fe}, \mathrm{Cr}$ and $\mathrm{Ni}$ from the substrate diffused outward to the coating. As a result, the structures of the aluminized coatings became more "homogeneous" after this 

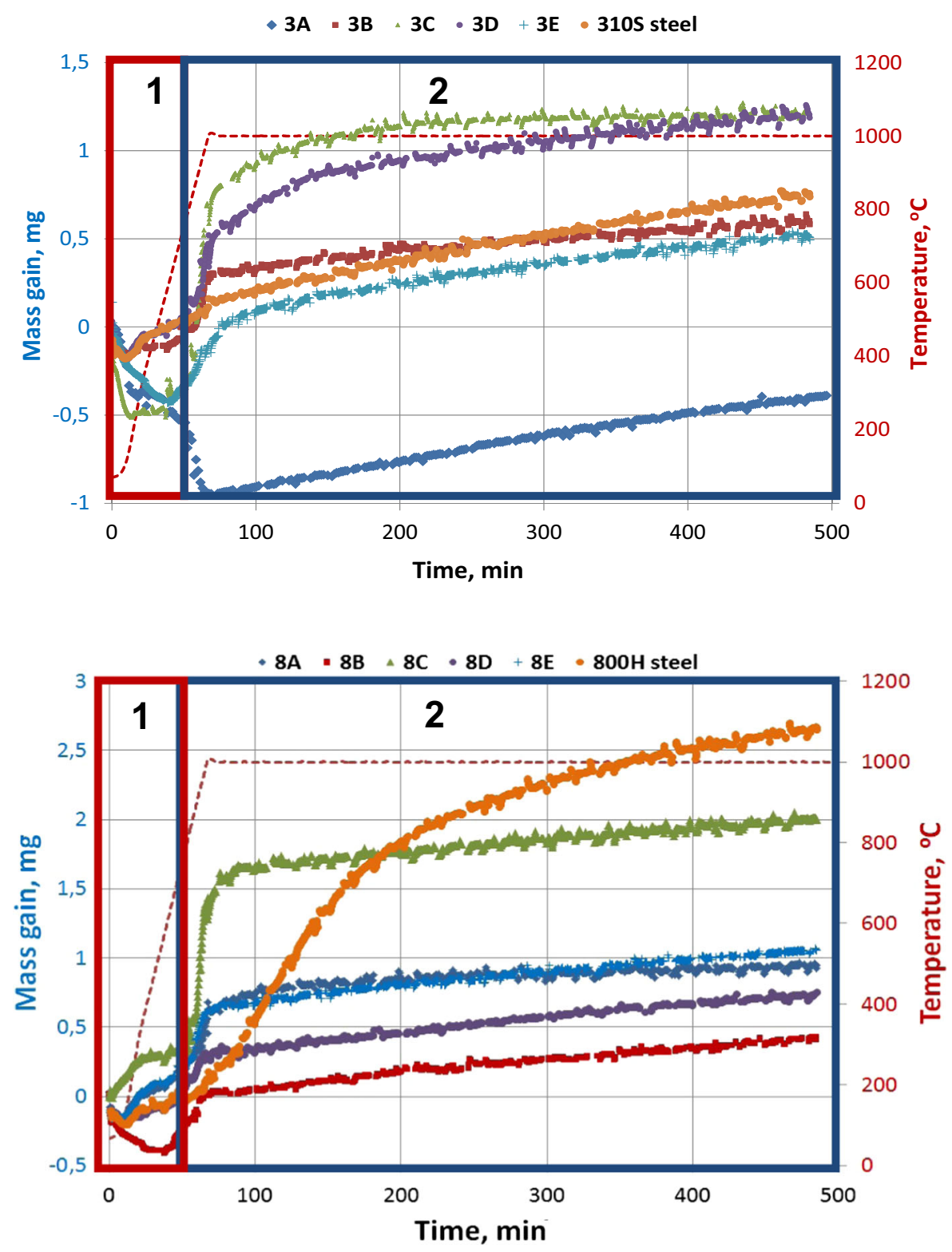

\section{Zone 1 - mass loss region due to transient oxidation Zone 2 - mass gain of the exposed samples in steam conditions}

Fig. 9 Summary of kinetic data for all studied samples exposed at $1000{ }^{\circ} \mathrm{C}$ for $8 \mathrm{~h}$, top $-310 \mathrm{SS}$ and coatings on $310 \mathrm{SS}$; bottom-800H and coatings on $800 \mathrm{H}$

"secondary" diffusion process originated by the high-temperature oxidation test. No Kirkendall porosity and micro-gaps between the layers of the aluminized coating occurred with this "secondary" diffusion process during the high-temperature oxidation test that should be outlined as a positive point. Some growth of the case depth during the high-temperature exposure may affect partial destruction and flaking of the top thin oxide layers adherent to the coatings $3 \mathrm{~B}, 3 \mathrm{C}, 3 \mathrm{D}$ and $8 \mathrm{C}$ and $8 \mathrm{D}$. Comparing the coated samples with two different substrates, the aluminized coatings on $800 \mathrm{H}$ demonstrated better adhesion and less micro-cracks. Probably, this case depth growth and modification in the phase composition also promoted the occurrence of occasional hairline cracks through the main aluminized layer. However, this hairline crack occurrence also may be related to fast heating at TGA testing $\left(1000{ }^{\circ} \mathrm{C} / \mathrm{h}\right)$ and probably rather fast cooling, i.e., to the created thermal stress at the testing. Anyway, the observed hairline cracks stopped at the transition zone for all the coated $310 \mathrm{SS}$ and $800 \mathrm{H}$ samples that indicate to satisfactory integrity of the coatings structures to the selected extreme testing conditions. It should be outlined that this TGA testing conditions distinguish from the industrial steam oxidation service conditions when final temperatures and especially heating ramps are lower. In the industrial conditions where service temperatures are significantly lower, i.e., 600$750{ }^{\circ} \mathrm{C}$, continuation of diffusion processes and related changes in the coating microstructures would be significantly minimized and thermal stresses would be also less. The diffusion-related bonding between the coating layers and with the substrate 


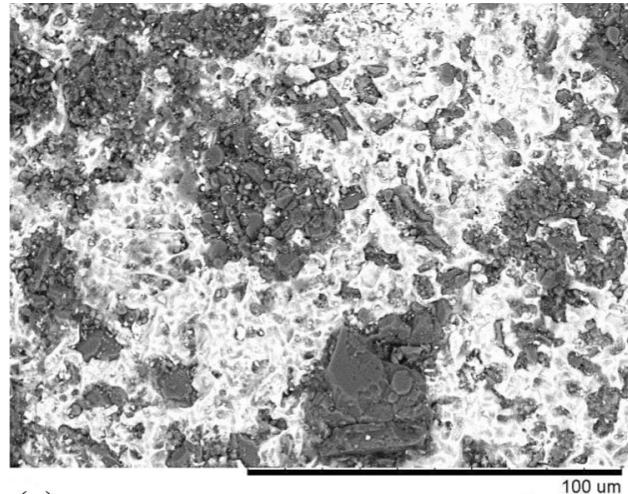

(a)

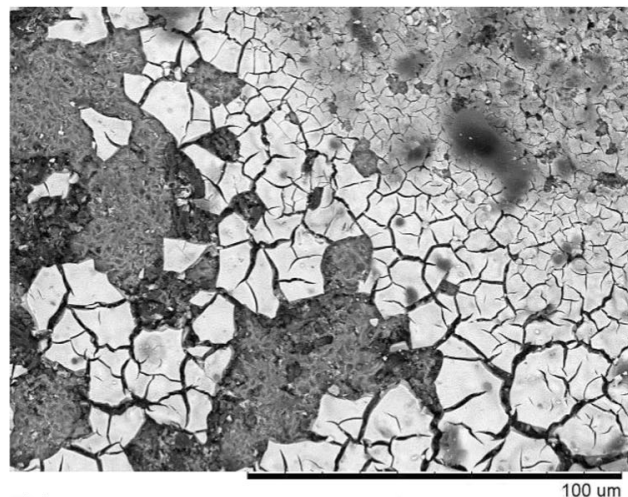

(c)

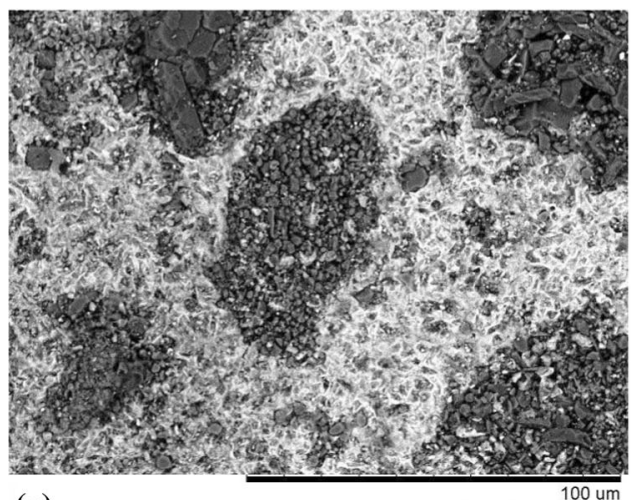

(e)

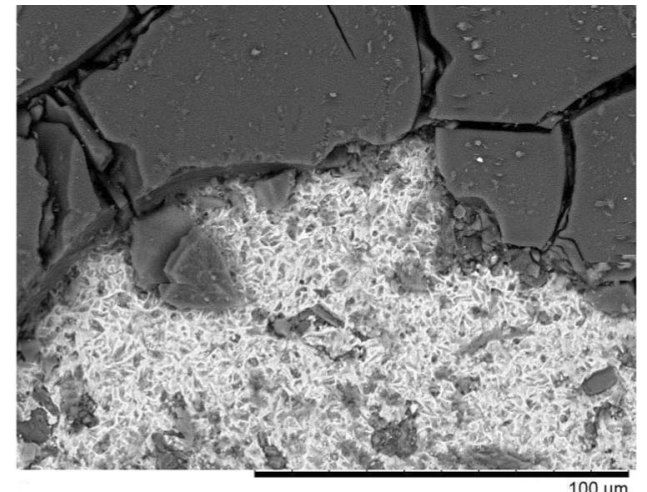

(b)

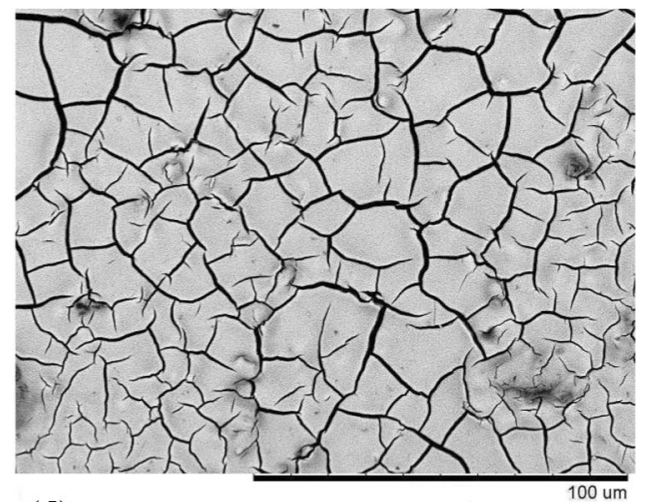

(d)

Fig. 10 Surface morphologies of the coated samples prior TGA tests: 3A-E

materials promotes the integrity of the aluminized coating structure at high-temperature oxidation. As opposed to the coated samples, bare $310 \mathrm{SS}$ and $800 \mathrm{H}$ experienced the formation of the scale on the surface $(\sim 10-15 \mu \mathrm{m}$ thick for $310 \mathrm{SS}$ and $\sim 10-20 \mu \mathrm{m}$ for $800 \mathrm{H}$ ) with its partial flaking-off and appearance of some cracking as well (see Fig. $7 \mathrm{f}, \mathrm{g}$ ).

Micro-hardness of the coatings after the TGA testing remained on the same level of the coating hardness before the testing. Thus, Knoop micro-hardness HK0.1 of the transition zone with low contents of $\mathrm{Al}$ remained in the range of $400-450 \mathrm{kgf} / \mathrm{mm}^{2}$, while HK0.1 of the main aluminized layer was in the range of $650-750 \mathrm{kgf} / \mathrm{mm}^{2}$ regardless of the substrate material. In particular, when the indenter was applied to the area very close to the transition zone, HK0.1 was $\sim 550$, but the major area of the main aluminized layer had consistent hardness values of $680-750 \mathrm{kgf} / \mathrm{mm}^{2}$, and only when the indenter was applied close to the top surface of the coatings, the
HK0.1 slightly decreased to $620-680 \mathrm{kgf} / \mathrm{mm}^{2}$. This is a common effect that also observed for as-aluminized steels, and it is dealt with lower consolidation of the surface of aluminized materials. Micro-hardness of the substrates (310SS and $800 \mathrm{H}$ ) was in the range of $170-200 \mathrm{kgf} / \mathrm{mm}^{2}$. Insufficient hardness reduction in the substrates can be observed when the indenter is applied close to the interface with the transition zone of the coating. The bare metals before and after oxidation testing also have a similar level of micro-hardness. This detailed hardness examination of the aluminized coatings has been conducted because of the observed changes in the aluminized coating architectures after high-temperature oxidation testing. The micro-hardness data determined for the materials before and after oxidation testing depending on the position, at which the indenter was applied, are summarized in Table 4. The determination of hardness of the formed chromiacontained scale for the bare $310 \mathrm{SS}$ and $800 \mathrm{H}$, even at 


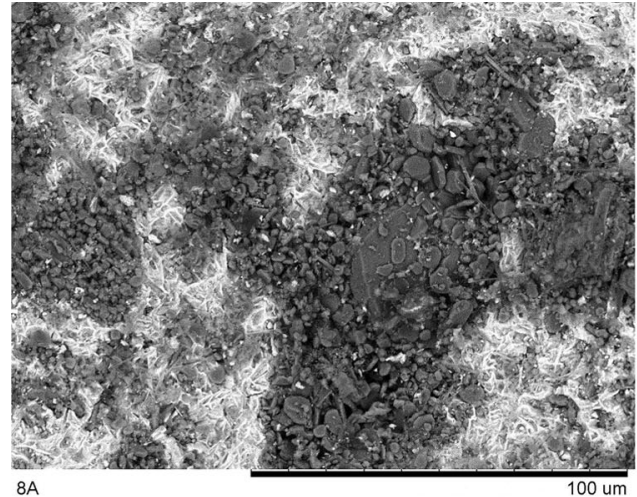

(a)

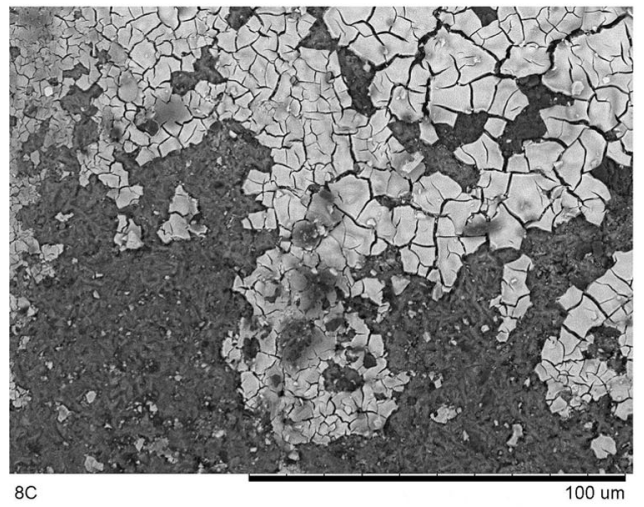

(c)

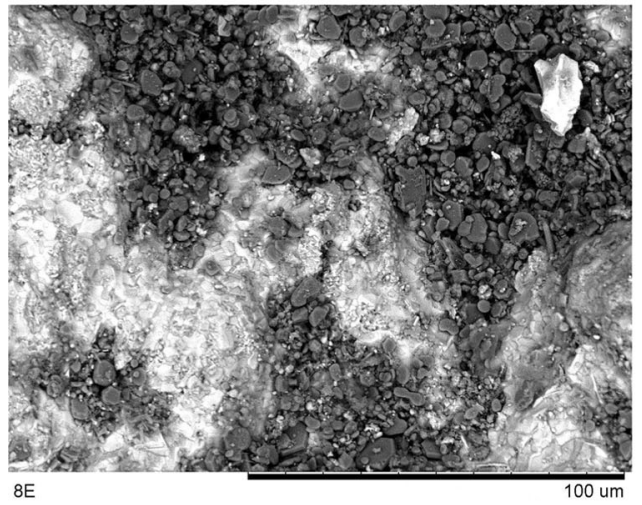

(e)

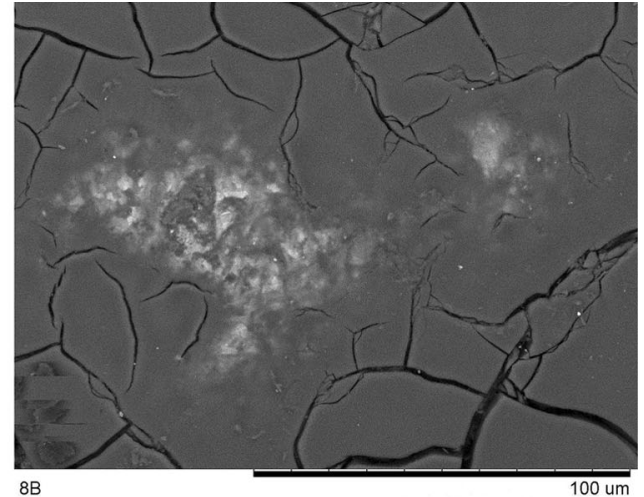

(b)

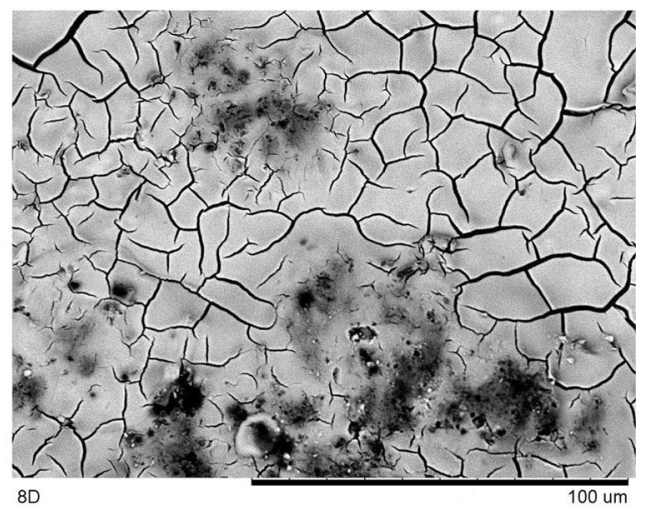

(d)

Fig. 11 Surface morphologies of the coated samples prior TGA tests: 8A-E

significantly lower indentation loads, was not possible due to its low hardness level and easy fracturing and breakaway. In general, the hardness values are defined by materials' phase composition and by structure, and they are commonly reduced with the presence of defects, e.g., flaws, porosity, micro-cracks. The obtained micro-hardness results indicate to the adequate integrity of the aluminized coating and to the relatively low effect of the applied steam oxidation testing conditions on these coatings.

The aluminized samples demonstrated their adequate corrosion resistance against the TGA oxidizing steam. As opposed to them, the reference $310 \mathrm{SS}$ sample tested in the same conditions exhibited uneven $\mathrm{Cr}$ contents on the surface (according to the EDS analysis, from 9 to $47 \mathrm{wt} . \%$ depending on different areas of the surface) and some nodule formation, despite a high content of $\mathrm{Cr}$ in the metal matrix, that corresponds to the breakaway oxidation phenomena ( $\operatorname{Ref} 7,8,35,36)$. Significantly elevated contents of Mn ranging from 8 to $24 \mathrm{wt} \%$, which also varied in different areas, can be related to the outward diffusion of $\mathrm{Mn}$ and to the formation of spinel phases, like $\mathrm{MnCr}_{2} \mathrm{O}_{4}$ (the content of $\mathrm{Mn}$ in the steel is only $1.25 \%$ according to MTR). Thus, the $\mathrm{Cr}_{2} \mathrm{O}_{3}$ inner sub-layer and the $\mathrm{MnCr}_{2} \mathrm{O}_{4}$ outer sub-layer may "compose" the scale (Ref 3638 ), but these layers are unevenly distributed that would affect the nodule and pitting formation. Comparing the formation of a thin alumina layer for the aluminized coatings during hightemperature oxidation with a chromia scale formation occurring at this process for uncoated $\mathrm{Cr}$-rich stainless steels, the former can be considered as preferable. It may be related to significantly slower formation of the aluminum oxide scale, 


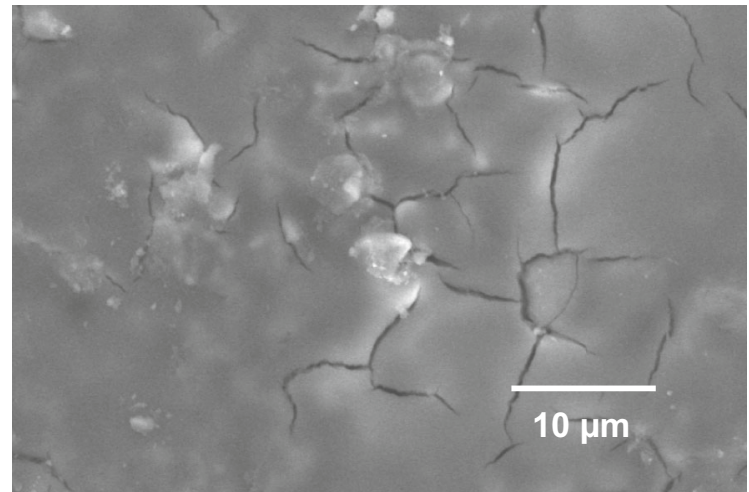

(a)

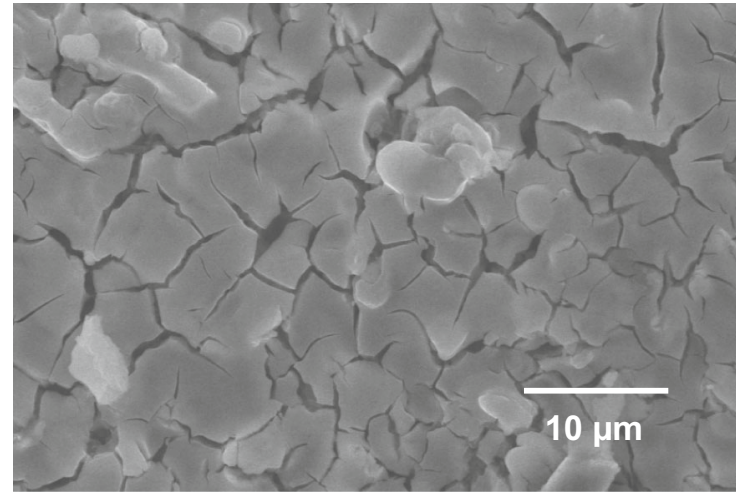

(b)

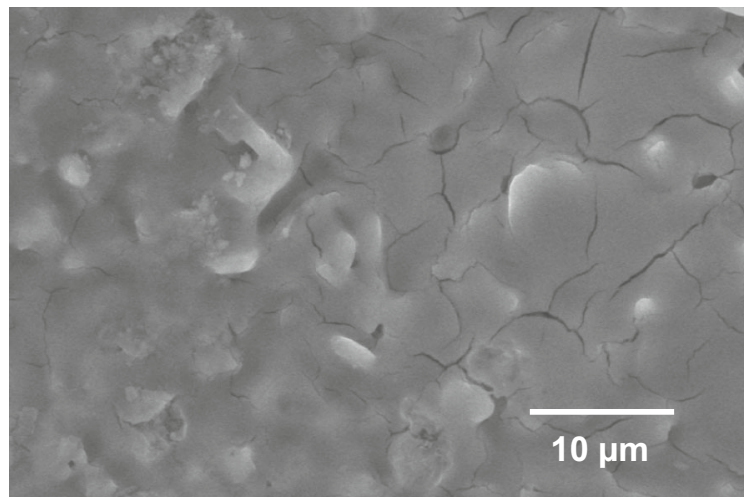

(c)

Fig. 12 Surface morphology of the top oxide coatings onto aluminized $800 \mathrm{H}\left(\mathrm{a} \mathrm{Al}_{2} \mathrm{O}_{3}\right.$ coating, b $\mathrm{SnO}_{2}$ coating, c $\mathrm{ZrO}_{2}$-based coating)

according to a number of studies conducted with stainless steels with sufficient contents of $\mathrm{Al}$ in the their compositions, and to a better adhesion of this scale to the steel substrates (Ref 39-41) and, hence, to significantly reduced breakaway. The mentioned point indicated for steels can be also applied for the aluminized coatings. Moreover, according to some works conducted by Perez et al. and Aguero et al. (Ref 41, 42), the high-temperature steam oxidation test results confirm the benefits obtained with the aluminide-based coatings. It should be outlined that, in the studied coatings, the major constituents are presented as intermetallides $\mathrm{Fe}(\mathrm{Cr}, \mathrm{Ni})_{x} \mathrm{Al}_{y}$, and, because of that, the "activity" of the elements, such as $\mathrm{Fe}$ and $\mathrm{Cr}$, in the intermetallides and the scale growth rate are reduced compared to the case when these elements are presented in bare steels.

Some authors (Ref 43, 44) connect failure of stainless steels in high-temperature steams with excessive growth of the chromia scale through its cracking and buckling due to the influence of hydrogen formed during steam oxidation. Thus, they assume that hydrogen penetrates through the scale accumulating in pores with creation of mechanical stresses at high temperatures with buckling leading to accelerated corrosion degradation. However, the hydrogen formation in the conditions considered in the present work may be hardly expected since basically hydrogen forms at steam dissociation at the combined action of high temperatures and high pressures (e.g., when pressures significantly exceed 4-5 MPa). Comparing bare metals tested and the aluminized coatings with sufficient thicknesses, it could be expected, according to the works (Ref 45-47), that the latter ones would significantly reduce the hydrogen permeation not only due to sufficient thickness of rather inert and well-consolidated aluminides, but also due to the alumina film formation on the coating surface. The data of effectiveness of the BN coating on stainless steel against hydrogen permeation reported by Tamura et al. (Ref 48) suggest to assume that the coating $\mathrm{E}$ (aluminized with a thin BN layer) may be also a promising solution for the steel protection against high-temperature oxidation when hydrogen may occur.

In the case of the uncoated $800 \mathrm{H}$ and especially $310 \mathrm{SS}$ after a short-time exposure at $1000{ }^{\circ} \mathrm{C}$, the chromium concentration in the steel near the scale interface is sufficient to form the protective chromia scale. However, in this study, some nodule formation was observed for 310SS (see Fig. 13f, h) that may be dealt with a local reduction in the chromium content and $\mathrm{MnCr}_{2} \mathrm{O}_{4}$ spinel formation. In this case, the integrity and bonding of the oxide scale become lower resulting in its breaking and detachment. This leads to the quicker oxidation of iron and nodule formation creating the surface structure similarly to the data presented earlier ( $\operatorname{Ref} 8,35)$. This structure basically contains two layers where the outer layer is iron rich with a small quantity of chromium, whereas the inner layer consists of mixture of $\mathrm{Cr}, \mathrm{Ni}$ and $\mathrm{Fe}$ oxides or/and spinel-type compounds, like $\mathrm{FeCr}_{2} \mathrm{O}_{4}$ and $(\mathrm{Ni}, \mathrm{Fe}, \mathrm{Cr})_{3} \mathrm{O}_{4}$, which are not protective (Ref $35,38,40$ ), and the nodules underneath. The EDS analysis showed that the content of Fe varied from 9 to more than $30 \mathrm{wt} \%$ in the nodule areas confirming the partial detachment of the $\mathrm{Cr}_{2} \mathrm{O}_{3}$ scale and oxidation of $\mathrm{Fe}$, while the "general" scale surface had significantly lower Fe contents but with the Cr contents of greater than 20 wt.\%. Thus, the Fe-rich nodules oxidize fast promoting the $\mathrm{Fe}-\mathrm{Cr}$-oxide scale formation and its growth leading to the breakaway process. The nodule formation on the surface of bare $800 \mathrm{H}$ was negligible. 


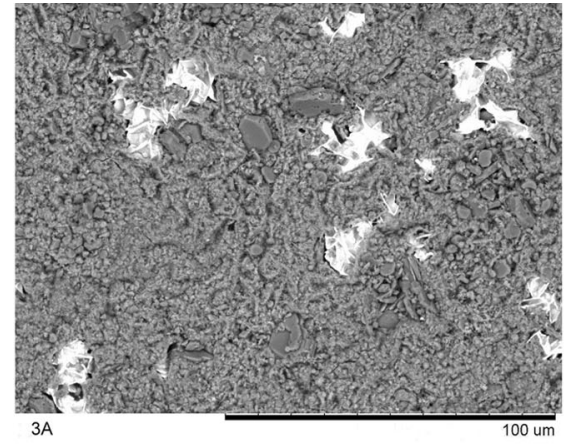

(a)

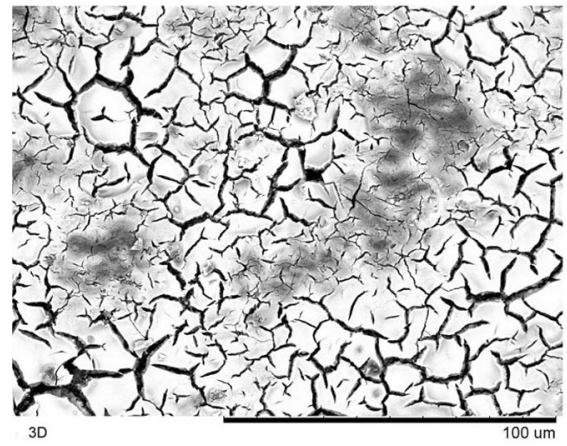

(d)

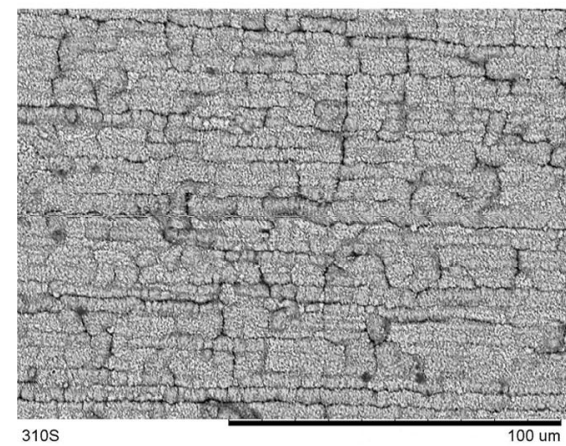

(g)

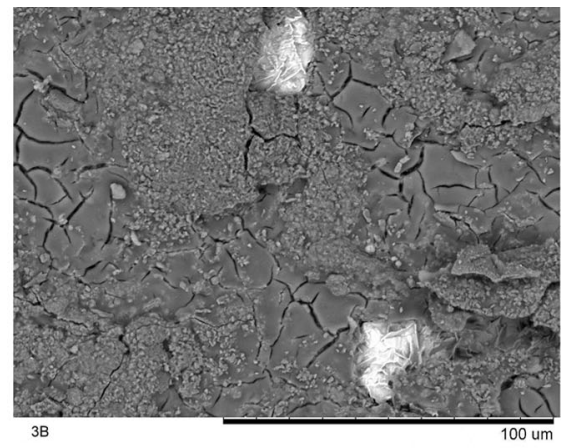

(b)

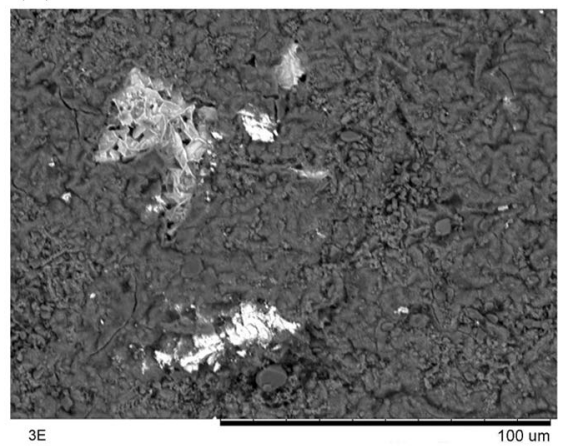

(e)

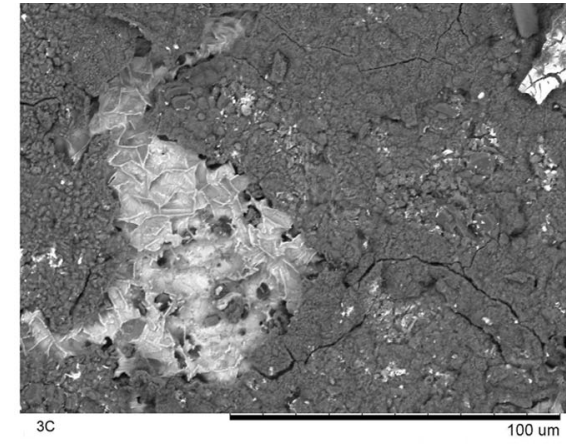

(c)

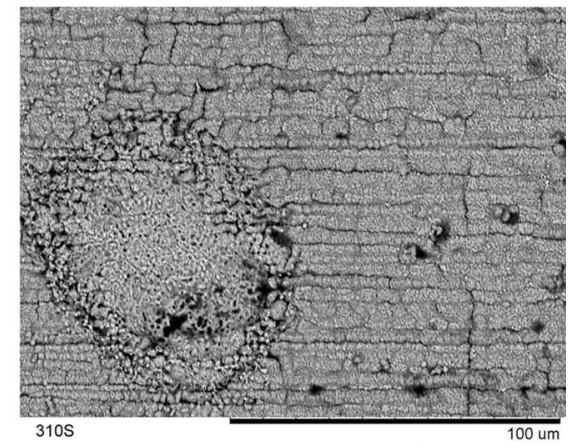

(f)

Fig. 13 Surface morphologies of the coated samples 3A-E and bare 310SS (F, G) after the TGA testing

However, the contents of $\mathrm{Cr}$ and $\mathrm{Ni}$ on the surface of $800 \mathrm{H}$ varied from $\sim 2$ to $40-45$ wt. $\%$ and from 6 to $30-33$ wt. $\%$, respectively. Also it might be speculated that, according to the studies (Ref 36, 41, 49, 50), some Cr volatilization may occur. These authors relate it through the formation of volatile chromium oxyhydroxide $\mathrm{CrO}_{2}(\mathrm{OH})_{2}$ particularly occurring at high oxygen partial pressures (much greater than 1 bar) (Ref 50). However, in the present work, the short-time testing was conducted in the water steam (not in pure oxygen where oxidation rate would be greater) at the pressure of 1 bar that is too low to induce evaporation of the $\mathrm{Cr}$-based species. In addition, the formation of $\mathrm{MnCr}_{2} \mathrm{O}_{4}$ spinel (that is highly possible according to the obtained EDS data) should significantly reduce the probability of the $\mathrm{Cr}$-oxyhydroxide formation (Ref 35,51$)$. Hence, the Cr evaporation at the initial stage of high-temperature steam oxidation is not assumed. Visual observation of the alumina crucibles used for the TGA testing also suggests the absence of $\mathrm{Cr}$ evaporation since these crucibles did not change their color after the tests (if Cr-based species are evaporated, they would deposit onto the crucible surface with changing its color). No $\mathrm{Cr}$ evaporation is also supported by the EDS data for the bare 310SS when rather large $\mathrm{Cr}$ contents on the surface (from 9 to more than $40 \mathrm{wt} . \%$ depending on the area) were detected. The question of evaporation of the $\mathrm{Cr}$-based species may require further studies of stainless steels, in particular of the long-time high-temperature oxidation, especially at elevated pressures. The presence of the rather thick ( $>100 \mu \mathrm{m})$ aluminized coatings eliminates the risk of evaporation of Cr-based species from steels and alloys.

The studied coatings can be manufactured through the thermal diffusion technology onto different size products, including onto the inner or inner and outer surfaces of long tubing. Since the coatings performance is related to the aluminides with a thin ceramic layer (formed by additional deposition and by oxidation of aluminides), these coating structures with similar compositions could be obtained for other types of steels, even less expensive. The formation of multilayered coatings with substantial thicknesses can be managed by the aluminizing process parameters. Small mass 


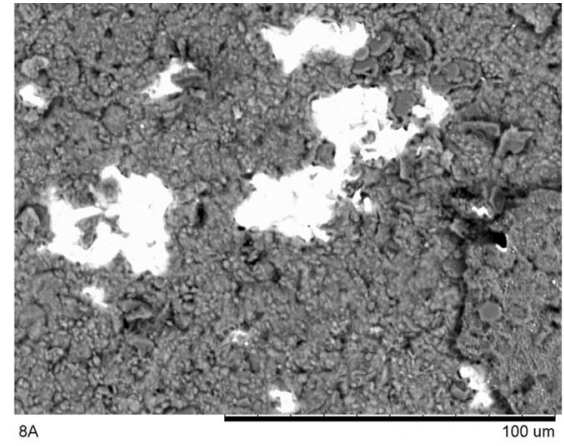

(a)

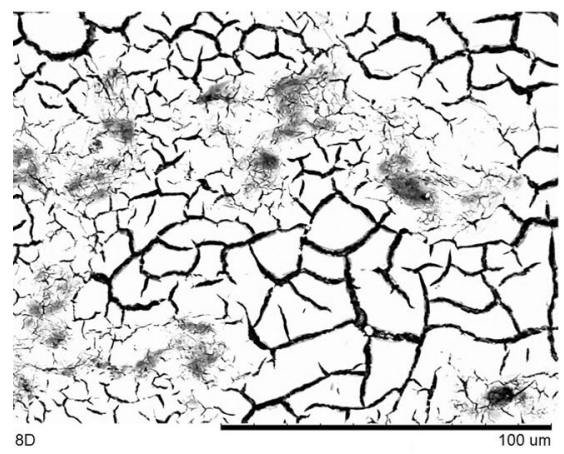

(d)

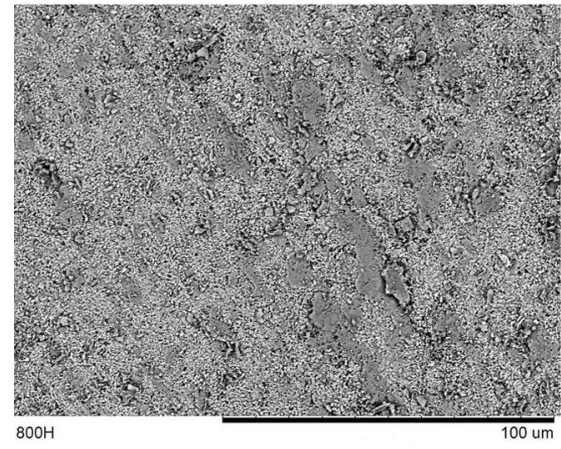

(g)

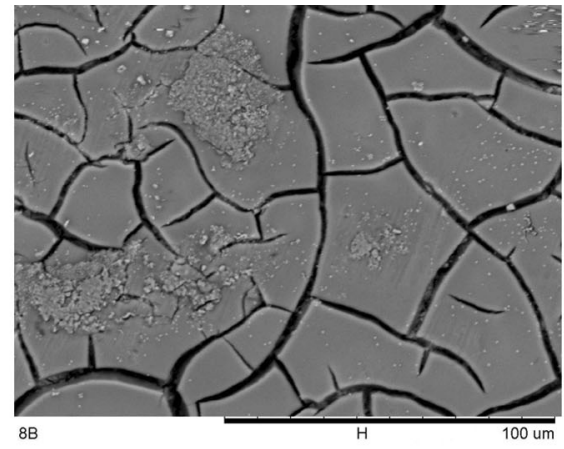

(b)

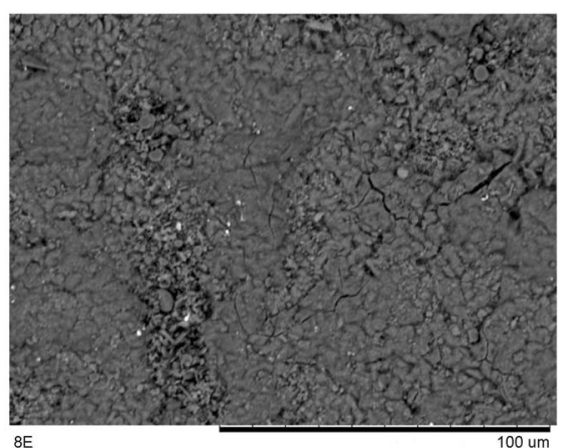

(e)

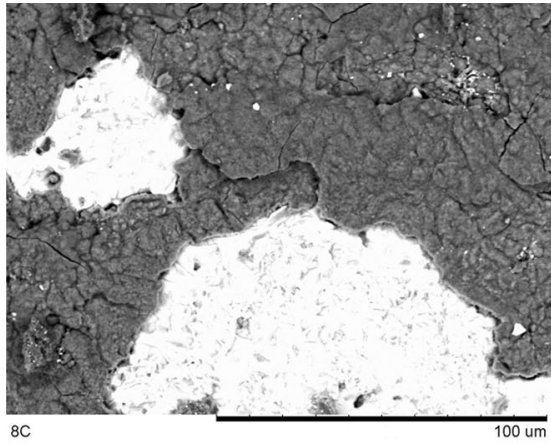

(c)

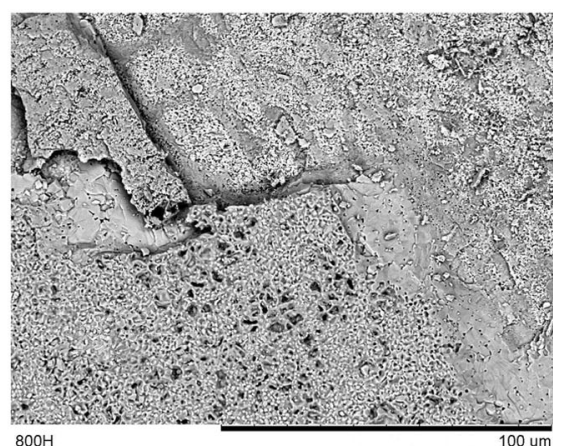

(f)

Fig. 14 Surface morphologies of the coated samples 8A-E and bare $800 \mathrm{H}$ (F) after the TGA testing

Table 3 Selected EDS analysis results (content of the major elements, wt.\%, on the surface)

\begin{tabular}{|c|c|c|c|c|c|c|c|}
\hline Sample & Al & $\mathrm{Cr}$ & $\mathbf{N i}$ & $\mathrm{Fe}$ & $\mathbf{Z r}$ & Mn & $\mathbf{O}$ \\
\hline $3 \mathrm{~A}$ & $46-50$ & $3-5$ & $6-9$ & $17-21$ & $\ldots$ & $\ldots$ & $8-10$ \\
\hline 3A-TGA & $48-54$ & $2.5-5.5$ & $4-5.5$ & $0.4-0.8$ & $\ldots$ & $\ldots$ & $42-48$ \\
\hline 3B-TGA & $50-54$ & $1-2.5$ & $0-0.5$ & $0.2-0.7$ & $\ldots$ & $\ldots$ & $45-49$ \\
\hline 3D-TGA & $0.5-1$ & $0.8-1.2$ & $\ldots$ & $\ldots$ & $68-72$ & $\cdots$ & $20-25$ \\
\hline 3E-TGA & $46-52$ & $4.5-6$ & $03-1.5$ & $0.8-2$ & $\ldots$ & $\begin{array}{l}\cdots \\
\ldots\end{array}$ & $36-40$ \\
\hline 310-TGA & $\ldots$ & $16-47$ & $0.1-2.2$ & $0.5-38$ & $\ldots$ & $8-24$ & $28-35$ \\
\hline 8A-TGA & $41-53$ & $2.5-3.4$ & $10-12$ & $0.5-1.2$ & $\ldots$ & $\ldots$ & $32-44$ \\
\hline 8B-TGA & $49-55$ & $2.3-3$ & $\ldots$ & $\ldots$ & $\ldots$ & $\ldots$ & $40-47$ \\
\hline 8D-TGA & $0.5-1$ & $0-1$ & $\ldots$ & $\ldots$ & $68-72$ & $\ldots$ & $20-25$ \\
\hline 8E-TGA & $40-49$ & $2.5-3$ & $0.8-1.8$ & $1.5-3$ & $\ldots$ & $\ldots$ & $44-46$ \\
\hline 800-TGA & $0.1-1.5$ & $2.5-45$ & $6.5-33$ & $3.5-56$ & $\begin{array}{l}\cdots \\
\ldots\end{array}$ & $\ldots$ & $17-38$ \\
\hline
\end{tabular}

The contents of $\mathrm{B}$, as the element with low atomic weight, for the samples $3 \mathrm{E}$ and $8 \mathrm{E}$ could not be determined (the EDS instrumentation used in the work did not have that capability) 

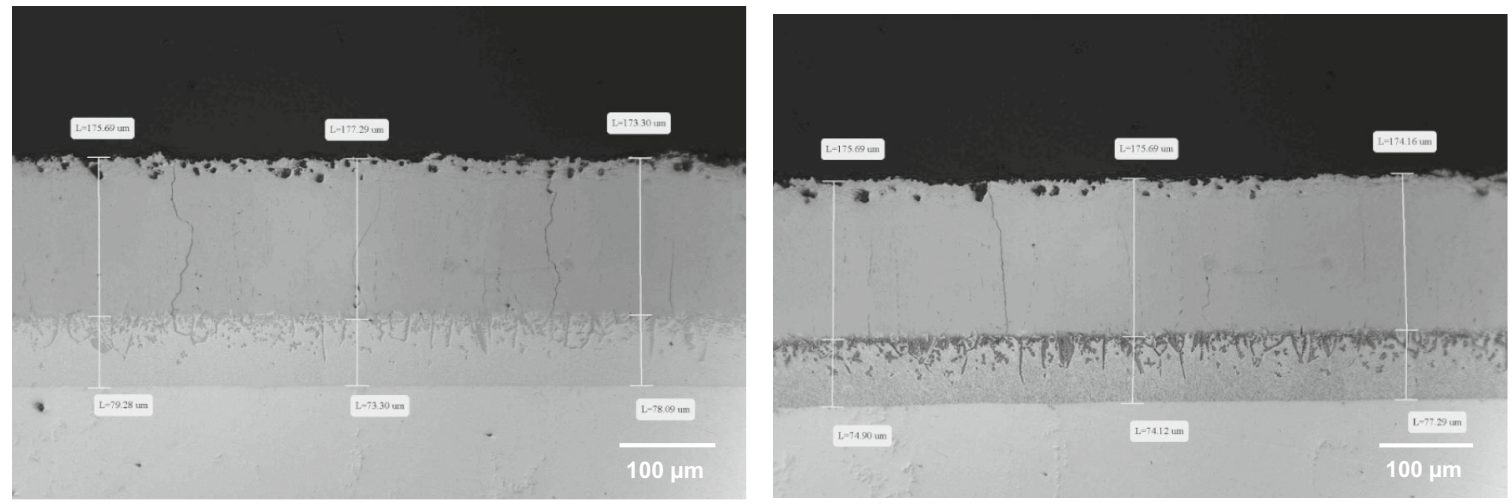

(a)

(d)
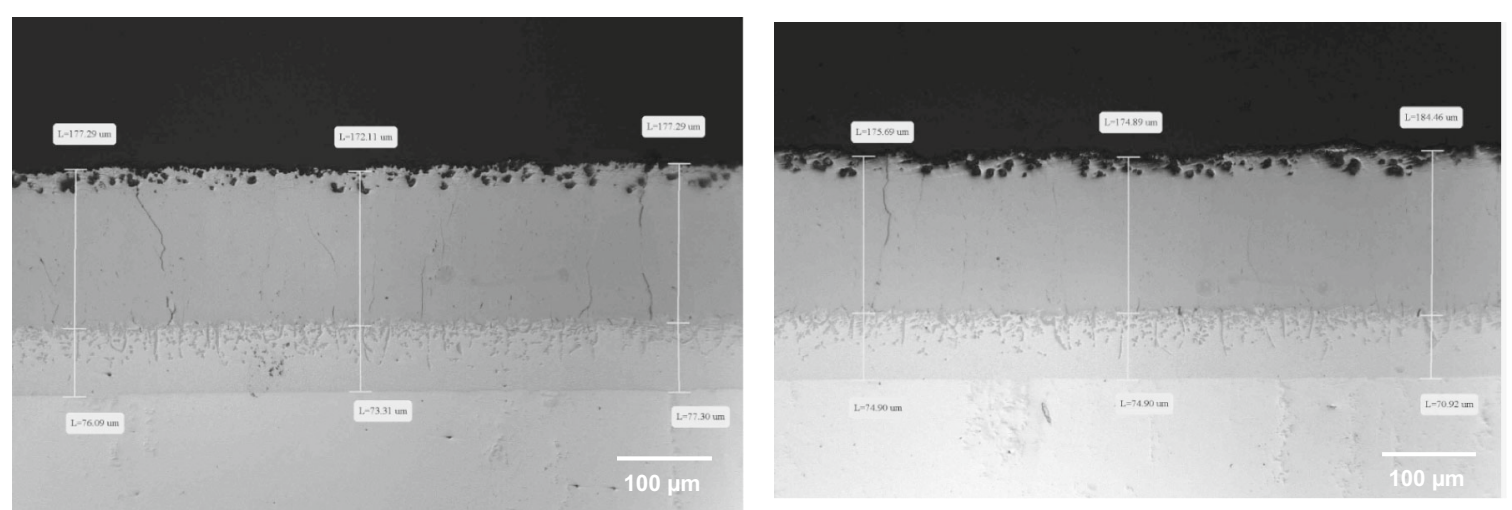

(b)

(e)
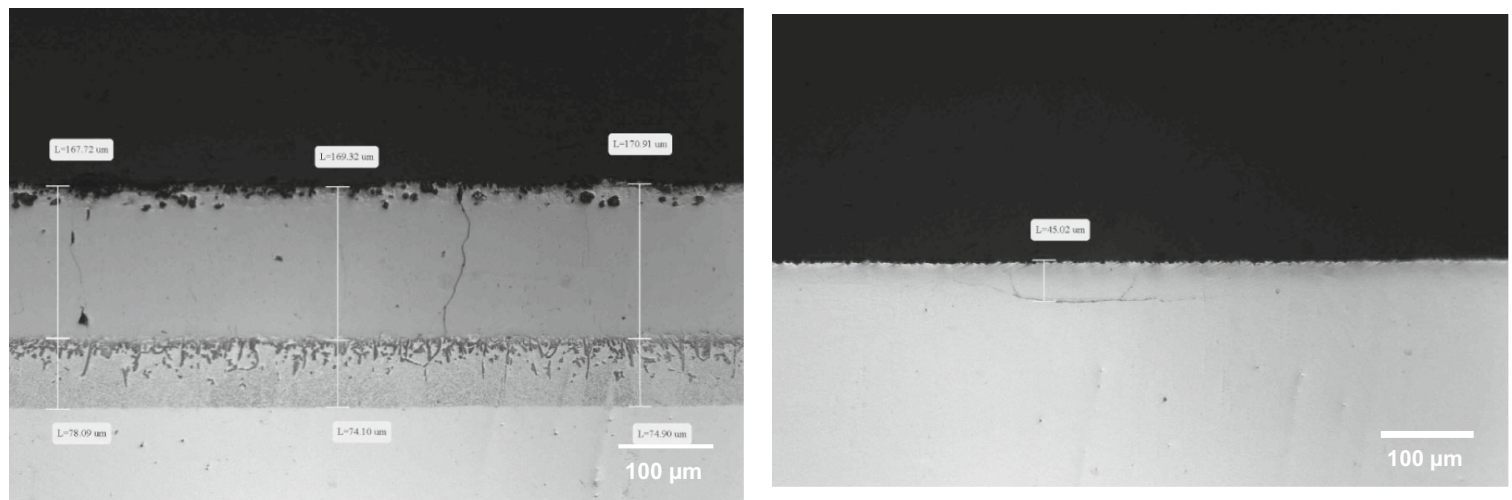

(c)

(f)

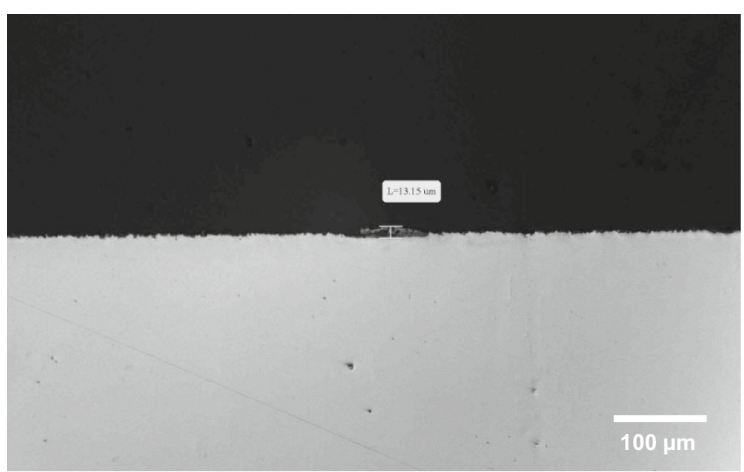

(g)

Fig. 15 Microstructures (cross sections) of the samples after the TGA oxidation testing (magnification $\times 200$ ). (a-e) coatings $3 \mathrm{~A}-3 \mathrm{E}$, respectively, (f, g) uncoated 310SS 


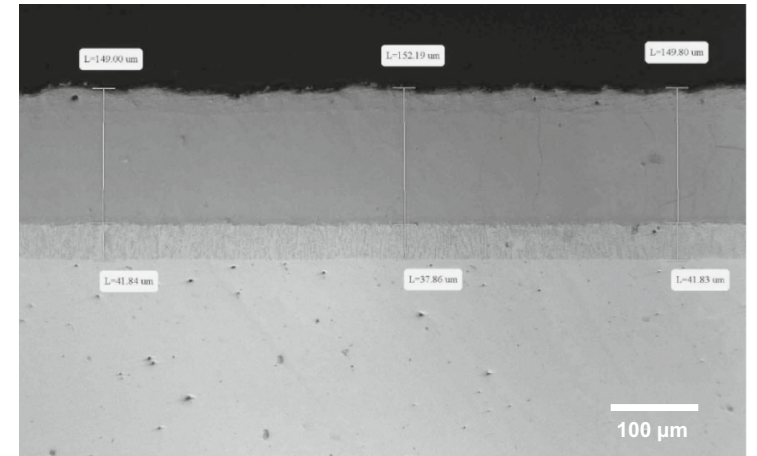

(a)

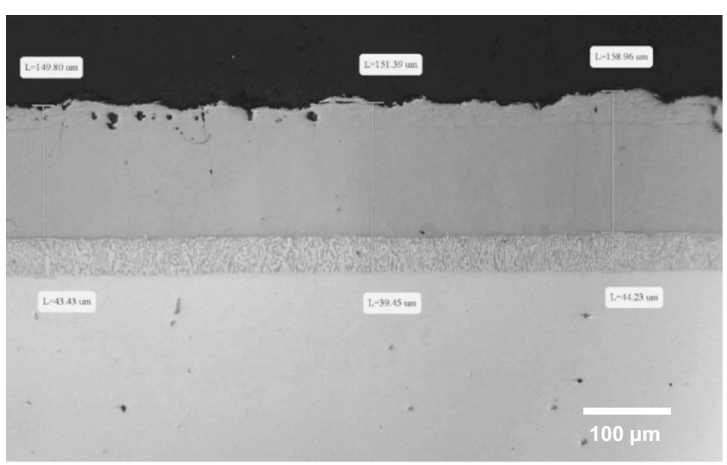

(b)

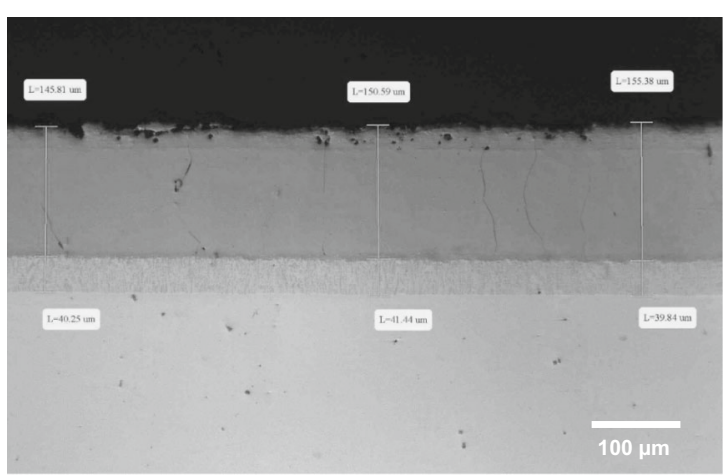

(c)

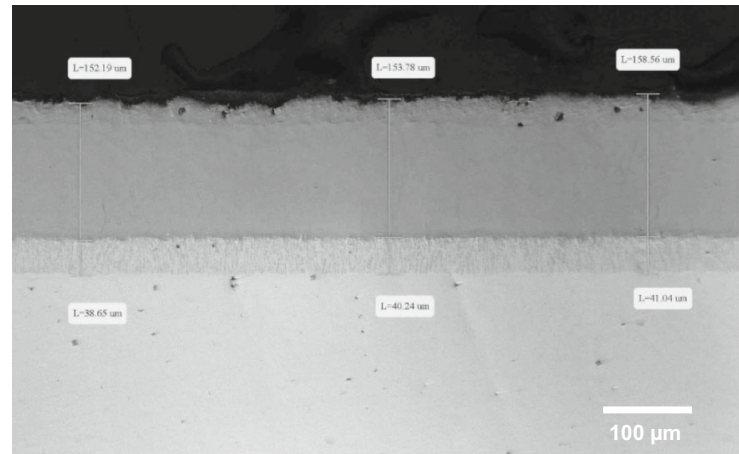

(d)

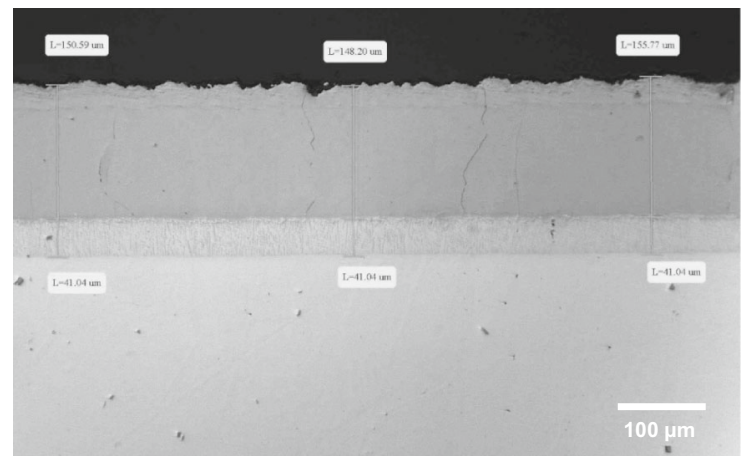

(e)

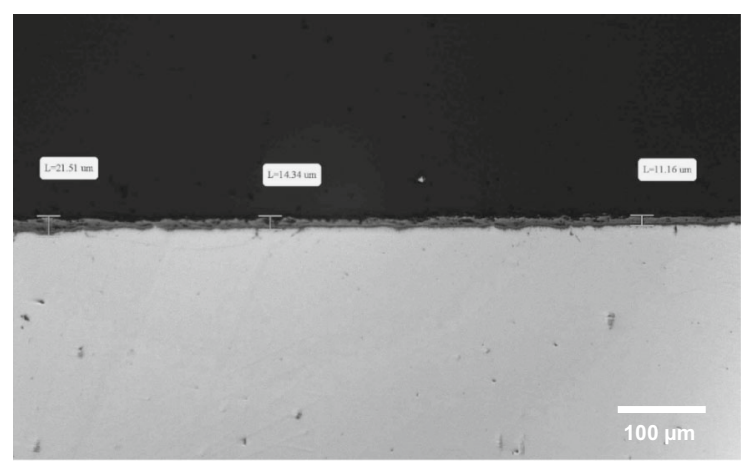

(f)

Fig. 16 Microstructures (cross sections) of the samples after the TGA oxidation testing (magnification $\times 200$ ). (a-e) coatings 8A-3E, respectively, (f, g) uncoated $800 \mathrm{H}$

\section{Table 4 Micro-hardness (HK0.1) determination results}

\begin{tabular}{lcc}
\hline Area of indentation & Before oxidation & After oxidation \\
\hline Substrate & $190-220$ & $170-200$ \\
& & $(10-20 \mu \mathrm{m}$ below coating) \\
Transition zone & $400-450$ & $400-450$ \\
Main aluminized layer & $650-750$ & $650-750$ \\
Close to transition zone & $550-570$ & $550-570$ \\
Middle & $700-750$ & $700-750$ \\
Close to top & $700-750$ & $650-700$ \\
Al-rich aluminized layer & $800-830$ & $\ldots$ \\
The results are similar for the coatings and substrates made of 310SS and $800 \mathrm{H}$ &
\end{tabular}


changes at the high-temperature oxidation adherent to the coated samples cannot be considered as a "negative" point since the formed aluminum oxide "skin" grown on the surface of rather inert aluminides increases the corrosion resistance, and it does not have the breakaway issue.

\section{Conclusion}

The TGA instrumentation and related approach have been employed, for the first time, for the quick preliminary evaluation of high-temperature oxidation resistance of the coatings on steel in simulated conditions, which exceeded the industrial conditions (i.e., at higher temperatures and with quicker heating). The obtained data may be used for identification of the oxidation effects occurring at the initial stage of oxidation corrosion and may assist the systematic studies of the long-time exposure (up to a few thousand hours) of the materials at high-temperature oxidation. The consideration of only mass change detection does not provide the adequate information, but the conjunction of the assessment of kinetic curves obtained from the TGA testing and microstructural examination and hardness determination of the coatings after high-temperature oxidation exposure is more effective for the materials evaluation and prediction of their behavior at the related corrosive environments.

According to the obtained results, e.g., kinetic curves, surface morphology and cross-section examinations, the multilayered aluminized coatings obtained through the thermal diffusion technology demonstrated promising corrosion resistance and have a promising potential for the protection of steels and alloys, e.g., $310 \mathrm{SS}$ and $800 \mathrm{H}$, against high-temperature oxidation conditions. The protection is related, to a significant extent, to the formation of the thin oxide films (mainly $\mathrm{Al}_{2} \mathrm{O}_{3}$ based) on the rather inert and consolidated aluminide coatings. The coatings based on aluminides with substantial thicknesses (greater than $100 \mu \mathrm{m}$ ) with a thin oxide film formed promote the protection of steels from the occurrence and subsequent removal of $\mathrm{Cr}_{2} \mathrm{O}_{3}$ scales with a lower adhesion and with potentially elevated volatility. The diffusion-related bonding between the layers in the aluminide-based coating systems promotes their integrity at severe oxidation conditions. Additional top layers from inert ceramic materials (e.g., oxides of the metals of III-IV groups and $\mathrm{BN}$ ) onto the main coating made of aluminides may be a positive step for improvement of oxidation resistance; however, it is important to avoid the breaking and destruction of this layer during the hightemperature oxidation exposure. Finally, bare materials 310SS and $800 \mathrm{H}$ experienced the formation of soft oxide scales with low adhesion, which can be partially detached, as well as nodules and surface micro-cracks. A better conclusion about suitability of the considered coatings may be done upon the extensive studies with longtime exposure; however, as mentioned above, the conducted short-time study could be helpful for preliminary evaluation.

\section{Acknowledgments}

The authors would like to acknowledge Foundry Research Institute in Krakow (Poland) for the support of the statutory project 7301/00 "High Temperature Studies." The support of Endurance
Technologies Inc. (Canada) dealt with the project initiation and coatings preparation and examination is appreciated greatly.

\section{Open Access}

This article is distributed under the terms of the Creative Commons Attribution 4.0 International License (http://creativecommons.org/ licenses/by/4.0/), which permits unrestricted use, distribution, and reproduction in any medium, provided you give appropriate credit to the original author(s) and the source, provide a link to the Creative Commons license, and indicate if changes were made.

\section{References}

1. I.G. Wright, A.S. Sabau, and R.B. Dooley, Development of Strain in Oxides Grown in Steam Tubes, Mater. Sci. Forum, 2008, 595-598, p 387-395

2. International Energy Agency (IEA), Technology Roadmap HighEfficiency, Low-Emissions Coal-Fired Power Generation, IEA, Paris, France, 2012

3. T. Dudziak, V. Deodeshmukh, L. Backert, N. Sobczak, M. Witkowska, W. Ratuszek, K. Chrusciel, A. Zielinski, J. Sobczak, and G. Bruzda, Phase Investigations under Steam Oxidation Process at $800{ }^{\circ} \mathrm{C}$ for $1000 \mathrm{~h}$ of Advanced Steels and Ni-Based Alloys, Oxid. Met., 2016, 87, p 139-158

4. N.K. Othman, N. Othman, J. Zhang, and D.J. Young, Effects of Water Vapour on Isothermal Oxidation of Chromia-Forming Alloys in $\mathrm{Ar} / \mathrm{O}_{2}$ and $\mathrm{Ar} / \mathrm{H}_{2}$ Atmospheres, Corros. Sci., 2009, 51, p 3039-3049

5. B. Pujilaksono, T. Jonsson, H. Heidari, M. Halvarsson, J.-E. Svensson, and L.-G. Johansson, Oxidation of Binary FeCr Alloys (Fe-2.25Cr, Fe$10 \mathrm{Cr}, \mathrm{Fe}-18 \mathrm{Cr}$ and $\mathrm{Fe}-25 \mathrm{Cr}$ ) in $\mathrm{O}_{2}$ and in $\mathrm{O}_{2}+\mathrm{H}_{2} \mathrm{O}$ Environment at $600{ }^{\circ} \mathrm{C}$, Oxid. Met., 2011, 75, p 183-207

6. T. Dudziak, L. Boron, V. Deodeshmukh, J. Sobczak, N. Sobczak, M. Witkowska, W. Ratuszek, and K. Chrusciel, Steam Oxidation Behavior of Advanced Steels and Ni-Based Alloys at $800{ }^{\circ} \mathrm{C}$, J. Mater. Eng. Perform., 2017, 26(3), p 1044-1056

7. H.E. Evans, A.T. Donaldson, and T.C. Gilmour, Mechanisms of Breakaway Oxidation and Application to a Chromia-Forming Steel, Oxid. Met., 1999, 52, p 379-402

8. S. Bsat and X. Huang, Corrosion Behaviour 310 Stainless Steel in Superheated Steam, Oxid. Met., 2015, 84, p 621-631

9. S.R.J. Saunders, M. Monteiro, and F. Rizzo, The Oxidation Behaviour of Metals and Alloys at High Temperatures in Atmospheres Containing Water Vapor: A Review, Prog. Mater Sci., 2008, 53, p 775-837

10. H. Asteman, K. Segerdahl, J.E. Svensson, and L.G. Johansson, The Influence of Water Vapour on the Corrosion of Chromia Forming Steels, Mater. Sci. Forum, 2001, 369-372, p 277-286

11. H. Asteman, J.E. Svensson, and L.G. Johansson, Oxidation of 310 Steel in $\mathrm{H}_{2} \mathrm{O} / \mathrm{O}_{2}$ Mixtures at $600{ }^{\circ} \mathrm{C}$ : The Effect of Water-VapourEnhanced Chromium Evaporation, Corros. Sci., 2002, 44, p 26352649

12. A. Aguero, Progress in the Development of Coatings for Protection of New Generation Steam Plant Components, Energy Mater, 2008, 3, p 35-44

13. A. Aguero, M. Gutierrez, R. Muelas, and K. Spiradek-Hahn, Overview of Steam Oxidation Behaviour if Al Protective Oxide Precursor Coatings on P92, Surf. Eng., 2016, 32, p 1-10

14. R. Streiff, Protection of Materials by Advanced High Temperature Coatings, J. Phys. IV, 1993, 3, p 17-41

15. Y. Tamarin, Protective Coatings for Turbine Blades, ASM International, Materials Park, 2002

16. B.B. Sudhangshu, High Temperature Coatings, Butterworth-Heinnemann, Oxford, 2007

17. N.V. Bangaru and R.C. Krutenat, Diffusion Coatings of Steels: Formation Mechanism and Microstructure of Aluminized Heat-Resistant Stainless Steels, J. Vac. Sci. Technol., B, 1984, 2(4), p 806-815

18. V. Rohr and M. Schutze, Diffusion Coatings for Heat Exchanger, Mater. Surf. Eng., 2004, 20(4), p 266-274 
19. C.-H. Bai, Y.-J. Luo, and C.-H. Koo, Improvement of High Temperature Oxidation and Corrosion Resistance of Superalloy IN-738LC by Pack Cementation, Surf. Coat. Technol., 2004, 183, p 74-78

20. D.J. Baxter, The Performance of Pack-Diffusion Aluminized and/or Chromized Low-Allow and Carbon Steels in Sulphur Containing Coal Gasifier Environments, High Temp. Technol., 1986, 4(4), p 207-218

21. A.B. Smith, A. Kempster, and J. Smith, Vapor Aluminide Coating of Internal Cooling Channels, in Turbine Blades and Vanes, Surf. Coat. Technol., 1999, 120-121, p 112-117

22. B.A. Pint and Y. Zhang, Performance of Al-Rich Oxidation Resistant Coatings for Fe-Base Alloys, Mater. Corros., 2011, 61(6), p 549-560

23. J.R. Nichols, Designing Oxidation-Resistant Coatings, JOM, 2000, 1, p 28-35

24. E.J. Mittemeijer and M.A.J. Somers, Ed., Thermochemical Surface Engineering of Steels, Elsevier-Woodhead Publishing, Cambridge, 2014

25. K.L. Choy, Chemical Vapor Deposition of Coatings, Prog. Mater Sci., 2000, 48, p 57-170

26. J.R. Davis, Surface Engineering for Corrosion and Wear Resistance, ASM International and IOM Communications, Maney Publishing, Materials Park, 2001

27. V. Zykova, J. Safonov, R. Walkowich, and S. Rogowska, Yakovin, Corrosion Properties of Nitride, Oxide and Multilayer Coatings on Stainless Steel and Titanium-Based Substrates, J. Phys: Conf. Ser., 2010, 223, p 012024

28. P.J.R. Smith, M.P. Taylor, H.E. Evans, N.E. Murray, C. McMillan, and J. Cherrington, The Oxidation and Interdiffusion of a Chromia Forming Multilayered TBC System, Oxid. Met., 2014, 81(1-2), p 47-55

29. M.P. Taylor, P.J.R. Smith, and H.E. Evans, Modeling of the Interdiffusion and Oxidation of a Multilayered Chromia Forming Thermal Barrier Coatings, Mater. Corros., 2017, 68(2), p 215-219

30. L.A. Dobrzanski, K. Lukaszkowicz, J. Mikula, and D. Pakula, Corrosion Resistance of Multilayer and Gradient Coatings Deposited by PVD and CVD Techniques, J. AMME, 2007, 28(1), p 12-18

31. T. Li, Y. Zhou, M. Li, and Z. Li, High Temperature Corrosion Behavior of a Multilayer CrAlN Coating Prepared by Magnetron Sputtering Method on a K38G Alloy, Surf. Coat. Technol., 2008, 202, p 19851993

32. J. Leppaniemi, P. Sippola, M. Broas, J. Aromaa, and H. Lipsanene, Corrosion Protection of Steel with Multilayer Coatings: Improving the Sealing Properties of Physical Vapor Deposition CrN Coatings with $\mathrm{Al}_{2} \mathrm{O}_{3} / \mathrm{TiO}_{2}$ Atomic Layer Deposition Nanolaminates, Thin Solid Films, 2017, 627(1), p 59-68

33. B. Chattopadhyay and G.C. Wood, The Transient Oxidation of Alloys, Oxid. Met., 1970, 2(4), p 373-399

34. T. Dudziak, L. Boron, M. Homa, R. Novak, N. Horton, R.M. Purgent, A. Siewiorek, N. Sobczak, and J.J. Sobczak, The Influence of Fabrication Process on the Initial Stages of Steam Oxidation Performed on HaynesR 282R Alloy at $760{ }^{\circ} \mathrm{C}$, J. Mater. Eng. Perform., 2017, 26(1), p 239-249

35. X. Cheng, Z. Jiang, D. Wei, J. Zhao, B.J. Monaghan, R.J. Longbottom, and L. Jiang, Characteristics of Oxide Scale Formed on Ferritic
Stainless Steels in Simulated Reheating Atmosphere, Surf. Coat. Technol., 2014, 258, p 257-267

36. X. Peng, J. Yan, Y. Zhou, and F. Wang, Effect of Grain Refinement on the Resistance of 304 Stainless Steel to Breakaway Oxidation in Wet Air, Acta Mater., 2005, 53(19), p 5079-5088

37. A.M. Huntz, A. Reckman, C. Haut, C. Severac, M. Herbst, F.C.T. Resende, and A.C.S. Sabioni, Oxidation of AISI, 304 and AISI, 439 Stainless Steels, Mater. Sci. Eng., A, 2007, 447, p 266-276

38. A. Col, V. Parry, and C. Pascal, Oxidation of a Fe- $18 \mathrm{Cr}-8 \mathrm{Ni}$ Austenitic Stainless Steel at $850{ }^{\circ} \mathrm{C}$ in $\mathrm{O}_{2}$ : Microstructure Evolution During Breakaway Oxidation, Corros. Sci., 2017, 114, p 17-27

39. Z. Yu, M. Chen, C. Shen, S. Zhu, and F. Wang, Oxidation of an Austenitic Stainless Steel With or Without Alloyed Aluminum in $\mathrm{O}_{2+}$ $10 \% \mathrm{H}_{2} \mathrm{O}$ Environment at $800{ }^{\circ} \mathrm{C}$, Corros. Sci., 2017, 121, p 105-115

40. B. Gleeson and B. Li, Cyclic Oxidation of Chromia-Forming Alloys: Lifetime Prediction and accounting for the Effects of Major and Minor Alloying Additions, Mater. Sci. Forum, 2004, 461-464, p 427-438

41. F.J. Perez and S.I. Castaneda, Study of Oxyhydroxides Formation on P91 Ferritic Steel and Slurry Coated by Al in Contact with $\mathrm{Ar}^{+}$ $80 \% \mathrm{H}_{2} \mathrm{O}$ at $650{ }^{\circ} \mathrm{C}$ by TG-Mass Spectroscopy, Surf. Coat. Technol., 2007, 201, p 6239-6246

42. A. Aguero, R. Muelas, A. Pastor, and S. Osgerby, Long Exposure Steam Oxidation Testing and Mechanical Properties of Slurry Aluminide Coatings for Steam Turbine Components, Surf. Coat. Technol., 2005, 200, p 1219-1224

43. F.H. Stott, F.I. Wei, and C.A. Enahoro, The Influence of Manganese on the High-Temperature Oxidation Iron-Chromium Alloys, Mater. and Corros., 1989, 40, p 198-205

44. J. Yuan, W. Wang, H. Zhang, L. Zhu, S. Zhu, and F. Wang, Investigation into the Failure Mechanism of Chromia Scale Thermally Grown on an Austenitic Stainless Steel in Pure Steam, Corros. Sci., 2016, 109, p 36-42

45. C.H. Henager, Chapter 8: Hydrogen Permeation Barrier Coatings, Materials for Hydrogen Economy, R.H. Jones and G.J. Thomas, Ed., CRC Press, Boca Raton, 2007, p 181-190

46. K.S. Forcey, D.K. Ross, and C.H. Wu, The Formation of Hydrogen Permeation Barriers on Steels by Aluminizing, J. Nucl. Mater., 1991, 182, p 36-51

47. H. Glasbrenner, A. Rerujo, and E. Serra, Hydrogen Permeation Behaviour of Hot-Dip Aluminized MANET Steel, J. Fusion Technol., 1995, 28(3P2), p 1159-1164

48. M. Tamura, M. Noma, and M. Yamashita, Characteristic Change of Hydrogen Permeation in Stainless Steel Plate by BN Coating, Surf. Coat. Technol., 2014, 260, p 148-154

49. H.C. Graham and H.H. Davis, Oxidation/Vaporization Kinetics of $\mathrm{Cr}_{2} \mathrm{O}_{3}$, J. Am. Ceram. Soc., 1971, 54(2), p 89-93

50. D.J. Young and B.A. Pint, Chromium Volatilization Rates from $\mathrm{Cr}_{2} \mathrm{O}_{3}$ Scales into Flowing Gases Containing Water Vapour, Oxid. Met., 2006, 66(3/4), p 137-153

51. G. Holcomb and D.E. Alman, Effect of Manganese Additions on the Reactive Evaporation of Chromium in Ni-Cr Alloys, Scr. Mater., 2006, 54, p 1821-1825 